University of Nebraska - Lincoln

DigitalCommons@University of Nebraska - Lincoln

2020

\title{
Mammal community structure through the Paleocene-Eocene Thermal Maximum
}

Danielle Fraser

S. Kathleen Lyons

Follow this and additional works at: https://digitalcommons.unl.edu/bioscifacpub

Part of the Biology Commons

This Article is brought to you for free and open access by the Papers in the Biological Sciences at DigitalCommons@University of Nebraska - Lincoln. It has been accepted for inclusion in Faculty Publications in the Biological Sciences by an authorized administrator of DigitalCommons@University of Nebraska - Lincoln. 


\section{Mammal community structure through the Paleocene-Eocene Thermal Maximum}

Danielle Fraser ${ }^{1,2,3}$ and S. Kathleen Lyons ${ }^{4}$

Affiliations: ${ }^{1}$ Palaeobiology, Canadian Museum of Nature, PO Box 3443 Stn “D”, Ottawa ON K1P 6P4

${ }^{2}$ Biology \& Earth Sciences, Carleton University, 1125 Colonel By Drive, Ottawa, Ontario, Canada K1S 5B6

${ }^{3}$ Department of Paleobiology, Smithsonian Institution, National Museum of Natural History, $10^{\text {th }}$ and Constitution NW, Washington, DC 20560-0121

${ }^{4}$ School of Biological Sciences, University of Nebraska Lincoln, Lincoln, NE, 68502 USA

Keywords: invasion, mammals, phylogenetic community structure, body size, beta diversity 


\section{ABSTRACT}

Human-mediated species invasion and climate change are leading to global extinctions and are predicted to result in the loss of important axes of phylogenetic and functional diversity.

However, the long-term robustness of modern communities to invasion is unknown, given the limited timescales over which they can be studied. Using the fossil record of the PaleoceneEocene Thermal Maximum (PETM; $56 \mathrm{Ma}$ ) in North America, we evaluate mammalian community-level response to a rapid global warming event $\left(5^{\circ}\right.$ to $\left.8^{\circ} \mathrm{C}\right)$ and invasion by three Eurasian mammalian orders and by species undergoing northward range shifts. We assembled a database of 144 species body sizes and created a time scaled composite phylogeny. We calculated the phylogenetic and functional diversity of all communities before, during, and after the PETM. Despite increases in the phylogenetic diversity of the regional species pool, phylogenetic diversity of mammalian communities remained relatively unchanged, a pattern that is invariant to the tree dating method, uncertainty in tree topology, and resolution. Similarly, body size dispersion and the degree of spatial taxonomic turnover of communities remained similar across the PETM. We suggest that invasion by new taxa had little impact on PaleoceneEocene mammal communities because niches were not saturated. Our findings are consistent with the numerous studies of modern communities that record little change in community-scale richness despite turnover in taxonomic composition during invasion. What remains unknown is whether long-term robustness to biotic and abiotic perturbation are retained by modern communities given global anthropogenic landscape modification. 


\section{INTRODUCTION}

Human activities are leading to the worldwide transplantation of species (Vitousek et al. 1997, McKinney and Lockwood 1999, Myers and Knoll 2001, Early et al. 2016) and widespread range shifts under anthropogenic climate and land use change (Parmesan 2006, Chen et al. 2011, Kerr

et al. 2015). Anthropogenic drivers are further implicated in significant changes in the formation of species assemblages, including biotic homogenization and loss of fundamental species associations (Vitousek et al. 1996, Vitousek et al. 1997, McKinney and Lockwood 1999, Parmesan and Yohe 2003, Vermeij 2005, Qian and Ricklefs 2006, Ricciardi 2007, Chen et al. 2011, Dornelas et al. 2014, Toth et al. 2014, Magurran et al. 2015, Early et al. 2016, Lyons et al. 2016a, Lyons et al. 2016b, McCreless et al. 2016, Seebens et al. 2017, Longman et al. 2018, Tóth et al. 2019). Significant losses of phylogenetic and functional diversity are also forecast under the current anthropogenic regime (Olden et al. 2004, Fritz and Purvis 2010, Huang et al. 2011). However, the timescales over which the responses of modern species assemblages can be studied are typically too short to address their long-term eco-evolutionary responses to abiotic and biotic perturbation (Dietl et al. 2015, Barnosky et al. 2017). Climate change (Zachos et al. 2001, Zachos et al. 2008) and species invasion via various mechanisms including migration over temporary land bridges, range expansions, and other long-distance dispersal modes (Simpson 1947, Vermeij 1991, Kerfoot and Weider 2004, Vermeij 2005, Ricciardi 2007, Woodburne 2010) have occurred numerous times throughout the past 66 Ma. The fossil record of these perturbations therefore provides an unparalleled opportunity for understanding and comparing their effects on timescales over which they are fully realized (Dietl et al. 2015, Barnosky et al. 2017). 
The transition from Paleocene into the Eocene was marked by a rapid global warming event of $5^{\circ}$ to $8^{\circ} \mathrm{C}$ known as the Paleocene-Eocene Thermal Maximum (PETM; 56 Ma) that followed an abrupt carbon isotope excursion (CIE) lasting $21 \mathrm{ky}$ or less, signifying a significant shift in the global carbon cycle (Wing 2000, Gingerich 2003, Wing et al. 2005, Gingerich 2006, Woodburne et al. 2009, McInerney and Wing 2011). The PETM was accompanied by invasion of North American faunas by Eurasian species (the first appearances of Perissodactyla, Artiodactyla, and Primates on the continent) and northward range shifts of endemic mammals (Table S1) (Bowen et al. 2002, Gingerich 2006, Burger 2012, Bowen 2014). The combined effects of invasion and rapid climate change were significant decreases in body size within and among mammal genera as well as considerable species turnover (Clyde and Gingerich 1998, Gingerich 2006, Woodburne et al. 2009, Secord et al. 2012, Rankin et al. 2015). However, changes in community assembly under the dramatic environmental and biotic changes of the PETM have hitherto not been explored. We therefore ask: Did the abiotic and biotic changes characteristic of the PETM alter the ways in which associations of species (nominally, communities) were assembled? Using a large dataset of mammal occurrences in the Big Horn and Clark Fork Basins in Wyoming (Gingerich et al. 1980, Gingerich 1989, 2001), we test for changes in community structure before, during, and after the PETM. Given the considerable change in the composition of the regional species pool through the PETM, we expect significant change in multiple aspects of community structure.

The appearance and loss of species via speciation, extinction, and immigration/emigration determine the size and composition of the regional pool of species available to colonize local sites (Rosenzweig 1995). Partitioning of species from the regional pool among local assemblages then occurs via the various processes that comprise community 
assembly. In general, the makeup of local assemblages is determined by the size and composition of the regional species pool as well as the outcomes of both species-species and speciesenvironment interactions (Rosenzweig 1995, Caley and Schluter 1997, Whittaker et al. 2001, Kraft et al. 2015). Due to divergent phylogenetic ancestry and evolutionary histories, species differ in their environmental tolerances, food preferences, and competitive abilities (Rosenzweig 1995, Pavoine and Bonsall 2010, Kraft et al. 2015). Species are therefore differently able to colonize the same sites and, thus, the composition of local species assemblages varies among sites typified by different biotic and abiotic conditions. Depending on inter alia the steepness of environmental gradients, competitive factors, and rates of dispersal, local assemblages can differ markedly or little in species composition (Leibold et al. 2004, Turner 2004, Cottenie 2005, Badgley 2010, Kraft et al. 2011, Baselga et al. 2012, Dobrovolski et al. 2012, Qian and Xiao 2012, Cadotte et al. 2013). At the local scale, classical niche theory predicts that the ways in which species are packed into physical and niche (i.e., trait and phylogenetic) space reflect assembly mechanisms (MacArthur and Levins 1967, Webb 2000, Losos 2008, Cavender-Bares et al. 2009). By quantifying changes in regional and local scale diversity as well as niche division, we can therefore infer changes in community assembly during the PETM.

The turnover, phylogenetic, and functional components of diversity are used as proxies for community assembly and are extensively studied in modern contexts (Webb et al. 2002, Graham and Fine 2008, Vamosi et al. 2009, Buckley et al. 2010, Davies and Buckley 2011, Swenson 2011, Cadotte et al. 2013). They are complementary measures of community assembly because they quantify the degree to which species share the landscape and available resources. Typically, the turnover component (often referred to as $\beta$ diversity) is measured as an average difference in species composition among sites using one of a variety of dissimilarity metrics 
(Baselga 2010, Qian and Xiao 2012) and is highest when environmental gradients are steep (Buckley and Jetz 2008). The functional (i.e., trait) and phylogenetic components of diversity are measures of niche space division that have been variously related to climate (Eronen et al. 2010a, Eronen et al. 2010b, Polly 2010, Qian et al. 2013, Fraser and Lyons 2017), competitive interactions (Schoener 1974, Connor and Simberloff 1979, Mayfield and Levine 2010, Safi et al. 2011, Fraser and Lyons 2017), speciation and extinction dynamics (Huang et al. 2011, Razafindratsima et al. 2012, Fraser et al. 2015), and biogeographic history (Fraser and Lyons 2017, Lawing et al. 2017). Traits, e.g., body mass, locomotor strategy, and diet, are most often used as proxies for the functional role of a species in a community (Oliveira et al. 2016). Phylogenetic distances among species (e.g., mean pairwise distances on the tree) are used to approximate unmeasured niche dimensions under the assumption that niches are phylogenetically conserved (Ricklefs 2010). Because the turnover, phylogenetic, and functional components of diversity vary in ways that are indicative of changes in the underlying ecology, they are useful measures of assessing changes in community assembly across the PETM.

Given the considerable climatological, morphological, and taxonomic changes that characterized the PETM, we expect that the ways species interacted with each other and their external environment also changed, resulting in changes to community assembly. Today, communities with the most species, typically those found in the tropics, are characterized by patterns of high taxonomic turnover among communities, phylogenetic evenness (the exclusion of closely-related species from the same community), and ecological redundancy. In contrast, species poor communities tend to be comprised of phylogenetically closely-related species with high morphological disparity and little taxonomic turnover from one community to another (Buckley and Jetz 2008, Safi et al. 2011, Oliveira et al. 2016, Fraser and Lyons 2017). The 
differences in community assembly among species rich and species poor communities appear to relate to differences in climate (insofar as climate impacts the energy available to species), rates of species immigration, and rates of resource competition (Buckley and Jetz 2008, Safi et al. 2011, Oliveira et al. 2016, Fraser and Lyons 2017). Making a space-for-time substitution, we predict that the rapid warming, species immigration, and increasing species richness that typified the PETM led the structure of mammal assemblages to more closely resemble modern, species rich communities, such as those in the neotropics. Therefore, we expect to see an increase in $\beta$ diversity, phylogenetic evenness, and lower morphological disparity during and potentially after the PETM.

Herein, we test for changes in regional and local species richness as well as rates of mammal first and last appearances during the late Paleocene and earliest Eocene of the Bighorn and Clark Fork basins in North America. We then quantify the functional, phylogenetic, and turnover components of assemblage structure to infer changes in the formation of species assemblages before, during, and after the PETM.

\section{MATERIALS AND METHODS}

Our dataset spans the latest Tiffanian ( $57.3 \mathrm{Ma})$ to earliest Wasatchian ( $55.5 \mathrm{Ma})$ North American land mammal ages (NALMAs) and includes the vast majority of mammal species that occur during the Paleocene-Eocene Thermal Maximum (PETM) in North America (Table S2). Mammal occurrences were downloaded from the Paleobiology Database using the group name "mammalia" and the following parameters $=$ Paleocene and Eocene, region $=$ North America, paleoenvironment $=$ terrestrial $($ see supplementary citation list for data sources). Occurrences were vetted and taxonomy was standardized to Janis et al. (1998) and Janis et al. (2008). We 
included only species occurring in localities from Wyoming (Bighorn and Clarks Fork Basins).

Wyoming is the only region in North America within which mammal-bearing localities of PETM age are definitive and thoroughly studied. The localities are therefore found in a relatively geographically restricted region (Fig. S1). As such, inferred assembly processes should be due to biotic interactions and regional scale differences in abiotic factors rather than broad-scale (e.g., continental-scale) differences in climate and habitat. Localities were assigned to NALMA subdivisions (Tiffanian 6, Clarkfork 1, Clarkfork 2, Clarkfork 3, Wasatch 0, and Wasatch 1-2) based on Gingerich (1989), Gingerich (2001), and Gingerich et al. (1980). Wasatch 0 encompasses the PETM. As in Rankin et al. (2015), we combine Wasatch 1 and 2. We calculated both gamma (regional) and alpha (local) diversity for each NALMA using the first-order Jackknife species estimator in the fossil R package (Heltshe and Forrester 1983, Smith and Belle 1984, Walther and Morand 1998, Vavrek 2012). We also calculated mean taxonomic differences using the Jaccard index between temporally adjacent time bins as a test of how much the taxonomic identity of species changed through the PETM.

\section{Estimating rates of first and last appearances}

To test whether invasion and rapid climate change increased rates of extinction or extirpation amongst North American mammals during the PETM, we estimated rates of first and last appearances throughout the interval. Herein, we use the terms first and last appearances because we recognize that many first appearances are a result of dispersal events (rather than true origination) both from Eurasia and northward from southern latitudes.

We created a NALMA subdivision by mammal species occurrence matrix for the Bighorn Basin of Wyoming (data described in earlier sections). To estimate rates of first and last 
appearances we used a capture-recapture model known as the Pradel seniority model (Pradel, 1996). We have chosen to use the Pradel model because it accounts for heterogenous and incomplete sampling (Liow \& Nichols, 2010). The Pradel model simultaneously fits five model parameters including survival probability (the probability that a species survives into interval $i+$ 1), probability of extinction ( 1 - survival probability), seniority (the probability that an extant species was also extant in interval $i-1$ ), net per capita diversification rate (the product of survival probability and the ratio of the number of new species appearing in interval $i+1$ to the number of species present at interval $i$ ), and sampling probability (the probability that an extant species is actually sampled in interval $i$ ).

It is important to simultaneously estimate the sampling probability because the fossil record is characterized by presences and absences that are influenced by sampling effort as well as biotic and abiotic taphonomic processes. As a result, the first observation of a fossil species is unlikely to be the true time of appearance; there is some probability that the species originated in preceding intervals. The same is true of species last appearances dates. That is, species have some probability of having gone extinct following their apparent last appearance in the fossil record (Liow and Nichols 2010). We therefore estimated species first appearances, last appearances, and sampling probabilities using MARK (White and Burnham 1999) executed via RMark (Laake 2013). We selected the best fitted model (the full model having time varying origination, extinction, and sampling parameters) using AICc. A model with time varying origination and sampling parameters and a constant rate of extinction was best fit (Table 1).

\section{Semiformal Supertree}


We created a semi-formal supertree for all mammals crossing the Paleocene-Eocene Thermal Maximum in our dataset, which includes $96 \%$ of species occurring in Wyoming from Tiffanian 6 to Wasatch 1 and 2 (Appendix I). We have also included species from before and after the PETM because their exclusion would bias the phylogenetic tip dating methods described below. Our approach is similar to that used by Smits (2015). The backbone of the mammal phylogeny is based on Tarver et al. (2016) and intergeneric relationships presented by Halliday et al. (2015). For genera not found in the recent phylogeny of Halliday et al. (2015), we used taxonomy as a guide; we assumed species from the same genus were sister taxa except where Janis et al. (1998, 2008) suggests otherwise. We also assume that genera were closely related to species in the same clade except where the clade was known to be polyphyletic (e.g., “condylarths"). Although our supertree may contain as of yet unknown polyphyletic genera, it reflects the current state of knowledge. All uncertain interfamilial and inter-generic relationships were represented by polytomies. Almost all inter-species relationships were represented by polytomies, given that comprehensive, species-level phylogenies do not exist for most Paleocene-Eocene mammals. Polytomies are not problematic for the types of analyses used herein (Finarelli and Badgley 2010, Raia 2010, Fraser et al. 2015, Fraser and Lyons 2017). As described below, we control for the alternative ways in which polytomies may be resolved using posterior distributions of tree topologies. Even though the phylogenetic trees used herein were not derived cladistically, they still represent testable phylogenetic hypotheses. Furthermore, use of taxonomy can yield similar results to using a phylogeny (Soul and Friedman 2015), so we do not expect systematic bias in our results.

We scaled the branch lengths of the phylogeny to reflect time in millions of years using species first and last appearance dates. We binned first and last occurrence dates into NALMA 
subdivisions because many of the dates are based on localities that are dated by biostratigraphy rather than direct dating methods (i.e., the dates can be constrained only to dates associated with the NALMA to which fossil localities can be referred). Dates for the NALMA subdivisions are based on paleomagnetism (Secord et al. 2006). We used several time scaling methods available in the paleotree $\mathrm{R}$ package (Bapst 2012) including the all branches additive or aba (Brusatte et al. 2008, Lloyd et al. 2012), minimum branch lengths or mbl (Laurin 2004), and cal3 dating methods (Bapst 2013). The aba method scales nodes to be as old as the first appearance of their oldest descendent and adds a user input time variable to every branch, which we set to $1 \mathrm{Ma}$. The mbl method scales all branches of a tree so that they are greater than or equal to the time variable of $1 \mathrm{Ma}$ while subtracting time added to later diverging branches from earlier diverging branches to maintain the proper temporal order of speciation events (Laurin 2004, Bapst 2012). The cal3 method requires estimates of instantaneous per-capita rates of speciation and extinction (Bapst 2013), which we calculated by estimating the sampling probability per bin using a likelihood function (make_durationFreqDisc in Paleotree) and converting to instantaneous or per capita rates (sProb2sRate in Paleotree) as per the example provided in the Paleotree documentation (Bapst 2012). The cal3 method then stochastically timescales trees using a probability distribution (gamma distribution with a shape parameter of two) of waiting times between speciation and first appearance in the fossil record (Bapst 2013).

For all time scaling methods, we generated posterior distributions of 1000 trees because all three methods allow for the random resolution of polytomies and, in the case of cal3, stochastic estimation of branch lengths based on sampling and rate estimates. We therefore performed all further analyses using the entire posterior distributions of tree topologies. Thus, the precise number of polytomies present in our supertree is unimportant. 


\section{Community Structure through Time}

To assess changes in mammal community assembly across the PETM, we used metrics of community structure including mean phylogenetic pairwise distance (MPD), the Net Relatedness Index (NRI) and Nearest Taxon Index (NTI) (Webb et al. 2002, Webb and Donaghue 2005, Qian et al. 2013), body mass dispersion (mean body mass difference among co-existing species; BM $_{\text {dist }}$ (Fritz and Purvis 2010, Fraser and Lyons 2017), body mass distributions (Brown and Nicoletto 1991, Bakker and Kelt 2000, Kelt and Meyer 2009, Lyons and Smith 2013, Smith and Lyons 2013), and multivariate dispersion (Anderson 2006, Anderson et al. 2006) as measures of phylogenetic diversity, functional diversity, and mean taxonomic dissimilarity, respectively.

We first created locality-by-species occurrence matrices for each NALMA subdivision, limiting our sample to include only localities with 5 or more species occurrences. Our sample therefore includes 809 individual occurrences of 144 unique mammal species (Table S2). Individual fossil localities are treated as individual communities assembled from a regional pool of species (i.e., all species present in a given time interval). We quantified each metric both with and without species whose first appearances occur during the PETM (Table S1). Excepting Artiodactyla, Perissodactyla, and Primates, we have no way of differentiating invasions from southern latitudes from true speciation events. For each metric, we then evaluated the degree of observed change between consecutive NALMAs using Cohen's D (Cohen's D = (mean observed first NALMA - mean observed second NALMA)/ pooled standard deviation). We consider absolute values of $d \leq 0.2$ small effect sizes and $d \geq 0.8$ large effect sizes, in keeping with convention (Cohen, 1988). 


\section{Phylogenetic Community Structure}

Using the semiformal supertree, we first calculated mean pairwise phylogenetic distances for the regional species pools in each time bin (Table S4) as a measure of how the phylogeneticrelatedness of species assemblages changed, given invasion from Eurasia, northward range shifts, and speciation events.

We calculated the Net Relatedness Index (NRI) for each NALMA subdivision using the picante R package (Webb 2000, Webb et al. 2002, Kembel et al. 2014). NRI is a standardized measure of mean pairwise phylogenetic distances among co-occurring species. We have chosen NRI from among the several available metrics for phylogenetic diversity because it shows less co-linearity with species richness (Oliveira et al. 2016). Furthermore, NRI outperforms other similar metrics such as the Nearest Taxon Index at detecting environmental filtering (Freilich and Connolly 2015). The Net Relatedness Index is calculated as:

$$
N R I=\frac{-1 * M P D_{o b s}-m e a n\left(M P D_{\text {exp }}\right)}{s t d\left(M P D_{\text {exp }}\right)}
$$

where MPDobs is the observed mean pairwise distance among species in the observed community

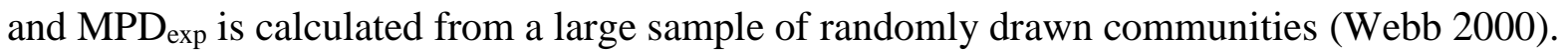
Positive values of NRI indicate that species in an assemblage (i.e. species that co-occur within a specific community) are more closely related than expected by chance (phylogenetically clustered). Negative values of NRI indicate that species in an assemblage are more distantly related than expected by chance (phylogenetically even). NRI values of zero indicate phylogenetic randomness (Webb 2000, Webb et al. 2002, Raia 2010).

We also calculated the Nearest Taxon Index (NTI) for each NALMA subdivision using the picante R package (Webb 2000, Webb et al. 2002, Kembel et al. 2014). NTI is a standardized measure of mean nearest taxon phylogenetic distances among co-occurring species. We have 
chosen to also include NTI because it outperforms NRI at detecting limiting similarity (Freilich and Connolly 2015), but opted to include NRI also because the two metrics are useful for detecting different assembly processes. The Nearest Taxon Index is calculated as:

$N T I=\frac{-1 * M N T D_{o b s}-\operatorname{mean}\left(M N T D_{\text {exp }}\right)}{\operatorname{std}\left(M N T D_{\text {exp }}\right)}$

(Equation 2)

where $\mathrm{MNTD}_{\mathrm{obs}}$ is the observed mean nearest taxon distance among species in the observed community and $\mathrm{MNTD}_{\exp }$ is calculated from a large sample of randomly drawn communities (Webb 2000). Positive values of NTI indicate that species in an assemblage (i.e. species that cooccur within a specific community) are more closely related than expected by chance (phylogenetically clustered). Negative values of NTI indicate that species in an assemblage are more distantly related than expected by chance (phylogenetically even). NTI values of zero indicate phylogenetic randomness (Webb 2000, Webb et al. 2002, Raia 2010).

NRI and NTI must be standardized using null models because they are intended as measures of phylogenetic separation among species in the same community relative to a random selection of species in the regional pool (Webb 2000). NRI and NTI are only meaningful if the pool from which random assemblages of species are drawn are potential colonizers of any given site. Using a species pool that combines all time periods would randomly place taxa that never co-occurred in time in the same communities, inflating the denominator of each metric and reducing NRI and NTI. Therefore, a null model comprised of temporally-separated species is not useful for the purpose of calculating such community assembly metrics. Although a null model combining all time periods would scale phylogenetic diversity in the different NALMAs allowing for comparison of relative levels of phylogenetic diversity across time, it would not address the question we are asking, which concerns inferring community assembly processes given patterns of regional-scale phylogenetic diversity. By asking how clustered or even 
community phylogenetic diversity is given the available regional species pool for a time period, we are asking about the relative importance of processes that can be inferred from these metrics (e.g., environmental filtering and limiting similarity) within each NALMA.

We chose to generate randomized communities for NRI and NTI calculation from the regional species pool for each time bin using a simple null model in which site richness is held constant but species occupancy is not (herein termed taxon shuffling) (Kembel 2009). For comparison, we also use the independent swap algorithm of (Gotelli 2000, Kembel and Hubbell 2006, Hardy 2008) because null models that maintain both grid cell richness and species occupancy yield the most reasonable rates of both Type I and Type II error (Kembel 2009). Swap algorithms start with the original occurrence matrix and involve randomly choosing submatrices with adjacent 1's and 0's then swapping them while retaining the row and column totals (Gotelli 2000, Gotelli and Entsminger 2001). However, we opted to present the results of the taxon shuffling model in the main text because the swap algorithm deals poorly with a nested occurrence matrix (those in which richness changes among sites and sites are occupied by subsets of the same species).

To test the degree to which our results are dependent on tree topology and resolution, we systematically degraded the phylogeny by collapsing increasing proportions $(25 \% \& 50 \%)$ of the phylogeny into polytomies using the degradeTree function in paleotree (Bapst 2012). The function randomly selects nodes in the phylogeny to collapse. We performed tree degradation 1000 times across a single phylogeny that was dated using the cal3 method and re-calculated NRI and NTI. To reduce computation time, we did not perform the tree degradation analysis for all dated trees in this study (i.e., we did not perform tree degradation using the maximum length 
branches and all branches additive dated trees nor across the entire posterior distribution of 1000 cal3 dated trees).

\section{Body mass dispersion}

Mammal body mass estimates were drawn from multiple literature sources (Alroy 1998a, Tomiya 2013, Smits 2015, Smith et al. 2018). Species for which body mass data were unavailable were assigned an average for their respective genus. Body mass estimates were therefore derived for $100 \%$ of taxa in our dataset (144 species). All body mass estimates were $\log _{10}$ transformed.

We use body mass as the functional trait of interest because mammalian body size is a determinant of many niche characteristics including inter alia geographic range size, population density, dispersal ability, life history, metabolism, and the thermal niche (Peters 1983).

Furthermore, body mass is collinear with many of the additional traits (e.g., diet) included in the calculation of functional diversity (Pineda-Munoz et al. 2016) and is a highly heritable trait in mammals (Smith et al. 2004). As a result, studies that include additional functional variables such as broad dietary category diet (e.g., herbivore, carnivore) do not yield patterns of functional diversity different from those expected for body mass dispersion alone (e.g., functional clustering in the tropics) (Safi et al. 2011, Oliveira et al. 2016, Fraser and Lyons 2017, Mazel et al. 2017, Fraser et al. 2018), suggesting that body mass does capture the major axes of niche variation (Rowan et al. 2016). Furthermore, inclusion of a large number of functional traits becomes redundant with phylogenetic diversity (Tucker et al. 2018). 


\section{Body Mass Distributions}

To assess possible changes in the regional species pool, we compared the shape of body mass distributions among the six different North American Land Mammal Ages used herein. Histograms were constructed for each NALMA using all species present. The shapes of the distributions were compared using Kolmorgorov-Smirnov two sample tests. Because we compared all pairwise combinations of NALMAs, we applied a Bonferroni correction.

\section{Mean Taxonomic Dissimilarity}

We calculated mean taxonomic dissimilarity using multivariate dispersion (Anderson et al. 2006, Fraser et al. 2014) for each NALMA subdivision and the Jaccard and Bray-Curtis faunal dissimilarity metrics. We then subject the dissimilarity values amongst sites in each NALMA to principal coordinates analysis (PCoA). We calculated Euclidean distances in PCoA space of all localities from the centroid using the R package vegan (Oksanen et al. 2012). Larger distances from the centroid indicate greater faunal dissimilarity among localities. We did not regress the Bray-Curtis or Jaccard index values against distance (i.e. distance decay of similarity), as has been used for modern species (Qian et al. 2009), because we have found such an approach to be highly influenced by species-area relationships, changes in distances among localities, and the number of taxa in the sample (results not shown).

\section{Testing for significant change in community assembly through time}

The core question of the present paper pertains to whether community assembly changed across the PETM. Regression analyses (i.e., linear regression) of community structure versus time are problematic because the sample size $(\mathrm{n}=6)$ is too small and thus lacks power. 
Furthermore, we show that taxonomic similarity among NALMAs is low, signifying high rates of turnover among time bins across the entire interval (Fig. 1A). Because biodiversity metrics can be sensitive to sampling intensity, including the number of samples (Gotelli and K.Colwell 2011), the number of species (Ulrich et al. 2018), and the occupancy or fill of the species-by-site occurrence matrix (Ulrich and Gotelli 2007a, b), we used a null model, which randomizes the assignment of each site to a particular time bin (Gotelli 2000). The model preserves species associations at each site (i.e., co-occurrence at the same site), the total number of species occurrences, as well as the number of sites per time bin. However, the model reshuffles patterns of species association that change among the time bins. All community structure metrics were then compared to this null model through calculation of standardized effect sizes (Cohen's D = (mean observed - mean null)/ standard deviation of null) to assess whether observed change among the time bins was more or less than expected based on changes in sampling intensity, number of sites, number of species, and matrix fill among bins. We consider absolute values of $d$ $\leq 0.2$ small effect sizes and $d \geq 0.8$ large effect sizes.

The null model we employ to test for differences among time bins necessarily differs from the null model we use during the calculation of NRI and NTI. The former is used to help differentiate significant from non-significant differences among time bins. The latter is used to assess community-scale clustering and evenness relative to random sample of species from the regional pool.

\section{Modern Comparison}

We downloaded spatially referenced geographic range data for modern non-volant Western Hemisphere mammals (Patterson et al. 2007), which uses the taxonomy of Wilson and 
Reeder (2005). The dataset includes 1366 species after the exclusion of a small number of unreadable or corrupted files. The Western Hemisphere mammal dataset has been used in other recent studies of community structure (Fraser and Lyons 2017, Polly et al. 2017). We sampled the ranges of extant Western Hemisphere mammals using a Behrmann equal area projection as per (Faurby and Svenning 2015) and $100 \mathrm{~km}$ by $100 \mathrm{~km}$ grid cells because smaller grid cell sizes are subject to bias (Hurlbert and Jetz 2007). We considered grid cells to be occupied by a species if the center of the cell intersected with its geographic range (Safi et al. 2011, Faurby and Svenning 2015). The result was a species by grid cell occurrence matrix, which we used for further analyses. We downloaded body size data for 1070 western hemisphere mammal species from the PanTHERIA database (Jones et al. 2009). Body masses were ln transformed before further analysis.

For each grid cell, we calculated the Net Relatedness Index using the modern mammal phylogeny of (Fritz et al. 2009), BM $_{\text {dist, }}$ and $\beta$ diversity. For NRI and NTI, we constructed randomized communities using the independent swap and taxon shuffling algorithms, as with the fossil communities. For $\beta$ diversity we used the $\mathrm{R}$ function spDistsN1 to calculate the great circle distances amongst grid cells. To calculate multivariate dispersion, we used a spatial window of $1000 \mathrm{~km}$ and subsampled grid cells using the inverse of the great circle distance as the probability of selection (similar to the approach of (Buckley and Jetz 2008). For each subsampled group of grid cells, we then performed the multivariate dispersion analysis and extracted the average distance of the focal grid cell from the centroid in PCoA space. For all three metrics, we plotted the values back onto projected maps of the Western Hemisphere under a Behrmann equal area projection. 


\section{RESULTS}

There is considerable turnover in community composition and increasing phylogenetic diversity (measured as mean pairwise distances) of the regional species pool through the sampled interval (Fig. 1A-B), which reflects lengthening of branches due to evolutionary time as well as first and last appearances (invasions and speciation). High rates of mammal first appearances (speciation plus northward range shifts and invasions) during the PETM are not matched by increasing extinction/extirpation, leading to both increased $\gamma$ (regional richness; Fig. 1C) and $\alpha$ diversity (local richness; Fig. 1D). Because our data record the high rate of species first appearances in North America during the PETM, despite declining sampling rate (Fig. 1C; purple dotted line), we reject data insufficiency as a driving factor for any of the patterns observed herein.

Except for the comparison between the Tiffanian 6 and Wasatch 1-2, the shape of the mammal body mass distribution is unchanged through the PETM (Clakfork 3 through Wasatch $0 ; p>0.05$; Table $2 \&$ Fig. 2;), suggesting little change in the functional composition of the regional species pool, despite considerable taxonomic turnover; Fig. 1A). All observed changes should therefore reflect changes in community assembly rather than functional changes in the regional species pool.

North American Paleocene-Eocene mammal communities show lower mean taxonomic dissimilarity and higher phylogenetic diversity than most modern temperate mammal assemblages (Fig. 3) and are most comparable to modern assemblages at subtropical latitudes and the southeastern United States (Fig. S2 \& Fig. S3). However, PETM mammal communities are more functionally homogenous than modern tropical assemblages (Fig. S3A), likely reflecting the smaller maximum body sizes of Paleocene through early Eocene mammals (Alroy 
1998a, Smith et al. 2010). It is well-documented that the fossil record is biased against species of small body size but, because PETM communities are dominated by relatively small species, further sampling is likely only to strengthen this result.

We observe increases in the Net Relatedness and Nearest Taxon Indices during the PETM (Fig. 3A-B; Table 3). Under null expectations, however, both the NRI and NTI of PETM mammal communities decline (Fig. 3A-B), thus yielding large values of Cohen's D (calculated as the standardized difference between the observed and null; Table 4). We interpret NRI as indicating a shift from marginally phylogenetically even to marginally clustered and NTI as indicating a shift from evenness to indistinguishable from random because they are centered on zero (Fig. 3A-B). The effect sizes for differences among the earliest NALMAs (e.g., Tiffanian 6 - Clarkfork 1) are low and sample sizes are low, suggesting low statistical power. The effect sizes for change from Clarkfork 3 through Wasatch 0 (the PETM; primary focus of the present study) are $>0.8$, indicating large mean differences (Table 3 ) and sufficient statistical power, given that both NALMAs are represented by $>20$ fossil sites. When comparing the changes in NRI and NTI across the PETM to spatial patterns of phylogenetic relatedness for modern Western Hemisphere mammals, however, we find that the change is similar in magnitude to variation observed within the same region (Fig. S2); the mean value of NRI changes from -0.55 to 0.64 , which is equivalent to the difference between northern Massachusetts and Nova Scotia (Fig. S2). Similarly, the change in NTI is equivalent to the difference between southern Florida and northern Florida. In neither case, do the mammal faunas vary considerably in richness or composition among the compared regions. We therefore suggest that the comparatively large effect sizes for Clarkfork 3 and Wasatch 0 are not indicative of biologically meaningful differences nor of low statistical power. 
The patterns we observe for the NRI and NTI are invariant to phylogenetic time-scaling technique and the loss of up to $50 \%$ of phylogenetic resolution (Fig. S4-5), suggesting that even major changes in tree topology would not fundamentally alter our results. Change in NRI and NTI are comparatively muted when using the independent swap algorithm to calculate within-bin null models (Fig. S6) because it is a conservative null model algorithm. That is, our findings related to NRI and NTI appear to depend on the null model of choice; use of the independent swap algorithm suggests that both NRI and NTI are inconsistent with phylogenetic clustering and evenness (Fig. S6). For NRI, the finding of marginally increased clustering is therefore equivocal.

Mean body mass dispersion declines slightly through the PETM (Fig. 3C) and effect sizes for change among NALMAs are moderate across the PETM (Table 3) but the standardized differences between null and observed values are low, indicating that the observed change is within null expectations (Table 4). Thus, observed change in body mass dispersion likely only reflects the well-documented decline in the body mass of some mammal species (Secord et al. 2012) and not a change in community assembly processes. Mean taxonomic dissimilarity increases from the latest Tiffanian to earliest Wasatchian but the change is similarly indistinguishable from null expectations (Fig. 3D; Table 4) although standardized effect sizes are moderate to high (Table 3). These non-significant findings are unlikely to be due to low statistical power, given that the PETM is well sampled (>20 sites) and we employed 1,000 iterations of each null model.

All community assembly metrics show approximately the same pattern of change when species that first occur during the PETM (putative immigrants and new species) are excluded (Fig. S7). 


\section{DISCUSSION}

During the Paleocene-Eocene Thermal Maximum (PETM), invasion by entirely new orders of mammals (Primates, Artiodactyla, and Perissodactyla) and range expansions among endemic North American mammals (Bowen et al. 2002, Gingerich 2006) led to increasing $\gamma$ (regional richness; Fig. 1C; black dotted line) and $\alpha$ diversity (local richness; Fig. 1D). From Clarkfork 3 (latest Paleocene) to Wasatch 0 (PETM), mean $\alpha$ diversity increased by $\sim 30 \%$. Following the PETM, there was an additional 15\% increase (Wasatch 1 and 2; Fig. 1C). Increases in $\alpha$ and $\gamma$ diversity are consistent with our finding of an enhanced rate of first appearances that is not matched by an enhanced rate of extinction (Fig. 1C). The changes in $\gamma$ diversity led to an overall decrease in taxonomic similarity (Fig. S1A) as well as increasing phylogenetic diversity of the regional species pool (Fig. 1B), which reflects a combination of evolutionary time and invasions.

The assembly of local communities is determined by a combination of the size and composition of the regional species pool as well as the outcomes of species-species and speciesenvironment interactions (Rosenzweig 1995, Caley and Schluter 1997, Whittaker et al. 2001, Kraft et al. 2015). Therefore, given the rapid abiotic and biotic changes of the PETM, we expected change in multiple dimensions of community structure. Using a space-for-time substitution, we predicted that the structure of PETM and early Eocene communities would resemble modern species rich communities, which are typified by phylogenetic evenness, ecological redundancy, and high turnover of species from one community to another (Buckley and Jetz 2008, Safi et al. 2011, Oliveira et al. 2016, Fraser and Lyons 2017), more than Paleocene communities. Aside from a statistically poorly supported increase in the Net Relatedness Index during the PETM, suggesting a small degree of phylogenetic clustering, we 
find little evidence for any marked changes in community structure, whether measured in using phylogenetic, trait-based, or $\beta$ diversity methods (Fig. 3). Contrary to our expectation and despite changes in richness and the taxonomic composition of the regional species pool (Fig. 1A-B), community assembly was relatively unchanged through the PETM.

Resource competition is a commonly invoked biotic driver of community assembly and an oft cited explanation for the structure of modern species rich communities, such as those in the modern neotropics (but see Fraser \& Lyons, 2017) (Buckley and Jetz 2008, Safi et al. 2011, Oliveira et al. 2016). At the regional scale, enhanced competition may translate to depressed rates of diversification or increased rates of extinction due to interspecific interactions resulting from increased overlap in resource use (i.e., niche saturation) (Gould 1980, Benton 1987, Raia et al. 2006, Liow and Stenseth 2007, Liow et al. 2015, Žliobaite et al. 2017). At the local scale, competition due to niche similarity may drive the degree to which species can coexist, which species do coexist, and how coexisting species share the available niche space (Schoener 1974). Given phylogenetic niche conservatism, competition for resources is expected to be particularly intense among closely-related species (Brown 1984, Webb et al. 2002, Wiens and Graham 2005, Losos 2008, Cavender-Bares et al. 2009, Ricklefs 2010) (Mayfield and Levine 2010). Theoretically, communities dominated by interspecific competition may show increased rates of competitive exclusion (partitioning of physical space) (Hardin 1960, Cavender-Bares et al. 2006, Cavender-Bares et al. 2009) or character displacement (partitioning of trait space or limiting similarity) (Schoener 1974, Ricklefs 2010). The phylogenetic evenness and high taxonomic turnover among modern neotropical communities have been used to suggest competitive exclusion in the face of high species richness and ecological redundancy (Safi et al. 2011, Oliveira et al. 2016, Fraser and Lyons 2017) . 
Our finding of similarity in community structure across the PETM is therefore particularly unexpected because the ecologies of the invading and resident taxa appear to have been similar. Both residents and invaders were comprised of numerous ungulate-like ("Condylarths" and artiodactyls, respectively) and arboreal mammals (e.g., multituberculates and primates, respectively) with similar body masses, dietary, and locomotor characteristics, suggesting general ecological similarity (McNab 1979, Peters 1983, McNab 1989, Kelt and Van Vuren 1999, Freckleton et al. 2003, Eronen et al. 2010a, Eronen et al. 2010b, Polly 2010, Polly et al. 2011). Invading primates, for example, shared locomotor (i.e., arboreality) and tooth shape characteristics with endemic North American mammals such as members of the Plesiadapiformes (Stroik and Schwartz 2018). Furthermore, immigrant taxa overlapped significantly in isotopic niche space with endemic clades (Secord et al. 2008), likely due to similarly $\mathrm{C}_{3}$-dominated, folivorous diets. Mixing of immigrant and endemic controphic species (those with similar niches and thus resource preferences), such as is apparent during the PETM, may have provided ample opportunity for interspecific resource competition (Cavender-Bares et al. 2004, Cavender-Bares et al. 2006, Cavender-Bares et al. 2009, Faurby and Svenning 2016, Fraser and Lyons 2017). Yet we find that, despite the increased regional and local richness during the PETM, community-scale measures of phylogenetic diversity, body mass dispersion, and $\beta$ diversity were relatively unchanged, suggesting either that species did not experience significant resource competition or varied ecologically in ways that are not captured by the ecological proxies discussed here.

Abiotic factors such as climate also influence rates of diversification and community assembly through the process of environmental filtering. Environmental filtering is a process whereby species are sorted along abiotic gradients according to their environmental tolerances 
(Soininen et al. 2007a, Soininen et al. 2007b, Soininen 2010), which, provided niches are phylogenetically conserved, may result in clustering of species in physical, niche, and phylogenetic space (MacArthur and Levins 1967, Lamanna et al. 2014). Environmental filtering is thought to be the dominant process responsible for the assembly of modern species poor communities such as those in the Canadian Arctic, which are characterized by phylogenetic clustering of species in communities and low taxonomic turnover from one community to the next (Safi et al. 2011, Fraser and Lyons 2017). Given that the PETM is characterized by significant and rapid climate warming of as much as $8^{\circ} \mathrm{C}$ over $21 \mathrm{ky}$, our expectation of community structure becoming more similar to that of modern neotropical communities may have been incorrect; perhaps, climate filtering was more important. However, we do not find changes in community assembly consistent with enhanced environmental filtering, as we might expect if PETM community assembly was similar to modern species poor communities.

Although it is difficult to infer process from pattern, if the events that characterize the PETM led to higher rates of resource competition, enhanced environmental filtering, or some combination thereof, we would expect significant changes in community structure as quantified using one or more of the metrics employed herein. What factors may have led to little change in community structure amongst mammal assemblages, despite the considerable biotic and abiotic perturbation typical of the PETM? We propose two possible explanations, i) the timescales over which we have evaluated the resilience of PETM mammal communities are sufficiently large to have masked short-term eco-evolutionary changes and ii) available niches were not entirely saturated, allowing for new species to exploit unfilled niche space.

The timescales over which modern studies of invasion are carried out are typically on the order of years or decades (Dietl et al. 2015). However, paleontological studies, such as ours, 
encompass thousands to millions of years. Even competitively-dominated communities may not show hard limits to richness over such evolutionary timescales (Cornell and Lawton 1992) (but see Alroy (1998b), Benson et al. (2016), and Close et al. (2019)) because they exist in a state of shifting dominance among the processes of speciation, extinction, dispersal, invasion, and disturbance. Furthermore, thousands to millions of years may allow for the regional species pool to replenish communities from which endemics have been extirpated and for significant evolutionary change to facilitate the coexistence of endemics and invaders; extirpations and replenishment of local communities may have occurred on timescales shorter than the resolution of the PETM record in Wyoming. Although there may have been short-term eco-evolutionary changes that we cannot observe at the current temporal resolution, our results indicate that mammal communities do not show long-term changes (> one million years) in community assembly during the PETM.

Niche filling is the degree to which the available niche space is occupied by species in a community (Schoener 1974, Brown 1984, Walker and Valentine 1984, Cornell and Lawton 1992, Wiens and Graham 2005, Clarke and Gaston 2006). Saturation of niche space, theoretically, leads to depressed rates of diversification, as available niche space is depleted (Moen et al. 2014). Invasion of such saturated communities, those where all available niche space is filled, is thought to result in enhanced resource competition and, potentially, the displacement or extinction of endemic species (Brown and Sax 2004, Qian and Ricklefs 2006, Sax and Gaines 2008, McCreless et al. 2016). The assembly of communities may also change as niches become saturated, resulting in character displacement and/or competitive exclusion (Dayan and Simberloff 1994, Dayan and Simberloff 1996, Dayan and Simberloff 1998). Therefore, the degree of niche filling plays an important role in community assembly by setting 
rates of speciation and extinction (Alroy 1998b) and determining community-scale responses to biotic perturbation such as invasion (Gill 1974, Cornell and Lawton 1992, Roopnarine and Angielczyk 2015). Over the past 66 million years, mammal communities show evidence of equilibrial diversity dynamics, suggesting that niche saturation is a common occurrence (Alroy 1998b, Benson et al. 2016, Close et al. 2019).

We find that high rates of mammal first appearances (speciation plus northward range shifts) and species invasion are not matched by high rates of extinction or extirpation, leading to both increased $\gamma$ and $\alpha$ diversity (Fig. 1B). Furthermore, we find no evidence of the long-term changes expected for accommodation of new species by a saturated, competitively-dominated communities amongst Paleocene-Eocene mammal communities (Fig. 1-3). That is, we find none of the changes in niche or physical space division that are predicted for modern communities and expected for the accommodation of new species if communities are saturated.

Unsaturated communities can result from a variety of factors including abiotic perturbations that reduce population levels, niche conservatism, and niche contraction (Chesson and Warner 1981, Price 1984, Cornell and Lawton 1992, Darroch et al. 2014). Both widespread environmental perturbation (e.g., warming, reduced Net Primary Productivity) and narrowing of niches (i.e., mammal body size reduction) are characteristic of the PETM in North America (Clyde and Gingerich 1998, Gingerich 2006, McInerney and Wing 2011, Secord et al. 2012, Rankin et al. 2015). Furthermore, unsaturated communities may be a common phenomenon resulting from the fact that local communities exist in a state of flux due to the processes of invasion, dispersal, extirpation, and disturbance (Mateo et al. 2017). The possible commonness of unsaturated communities is exemplified by the numerous modern colonization events that have resulted in a higher richness than prior to the invasion (Sax and Brown 2000, Sax et al. 
2002, Fridley et al. 2007, Jackson and Sax 2010, Dornelas et al. 2014, Tóth et al. 2014). We suggest, therefore, that PETM mammal communities in North America may have been unsaturated, at least at the timescale and spatial resolution of the current study, reducing the need for compensatory changes in community assembly despite increasing species richness.

\section{Conclusions}

Throughout the history of life, species invasions have occurred numerous times, although episodically (Simpson 1947). Invasion may be an ecological rule (Vermeij 2005). Furthermore. numerous modern ecological studies show that invasions do not necessarily lead to declining local richness but rather to increasing turnover of the species that occupy invaded local communities (Sax and Brown 2000, Sax et al. 2002, Fridley et al. 2007, Jackson and Sax 2010, Dornelas et al. 2014, Tóth et al. 2014); although invasion may lead to replacement of endemics by invaders, richness and local productivity may be retained. Herein, we show that North American mammal community assembly was relatively unchanged despite the rapid climate changes and invasion of Eurasian and southern-latitude species that typified the PETM.

Although the species composition of the regional species pool certainly changed and the regional and local species richness increased, we find none of the eco-evolutionary changes expected for the accommodation of invading species by communities in which niches are saturated. If most communities exist below the level of niche saturation (Vermeij, 1991a; Ricklefs 2004) due to extirpation, dispersal, invasion, and disturbance that prevent communities from ever reaching carrying capacity, they may ultimately be able to absorb invading species.

Our findings are consistent with modern studies that show little impact of invasion on local-scale species richness (Sax and Brown 2000, Sax et al. 2002, Fridley et al. 2007, Jackson 
and Sax 2010, Dornelas et al. 2014, Tóth et al. 2014), but differ from those that show changes in other aspects of community structure such as $\beta$ diversity (e.g., Tóth et al., 2014). Further, they point to long-term robustness of past terrestrial mammal communities in the absence of anthropogenic influences. What remains unknown is whether the long-term robustness of mammalian communities is retained in the modern. Will anthropogenic global landscape modification ultimately limit the robustness of communities to human-assisted species transplantation and climate change? Although rates of invasion and global extinctions are not yet unprecedented (Vermeij 1991, 2005, Barnosky et al. 2011), landscape modification may be the deciding factor in whether communities retain their richness and ecological functions.

\section{Acknowledgements}

We thank Drs. R. Bonduriansky and S. R. Connolly for their service as editors. We also thank two anonymous referees for helpful reviews of previous iterations of this manuscript. We thank Dr. S. Wing for constructive comments on an earlier iteration of this manuscript. We also thank Dr. Peter Buck and the Smithsonian Institution for a Peter Buck Postdoctoral Fellowship awarded to DF. SKL was supported, in part, by NSF DEB 1257625 and 1744223 . This is ETE publication \#411.

\section{Author Contributions}

DF conceptualized the study, acquired and organized data, carried out all data analyses excepting analysis of body size distributions, wrote the original draft of the manuscript, and reviewed and edited all iterations of the manuscript. SKL carried out the analysis of body size distributions, 
wrote the related methods and results sections of the manuscript, and reviewed and edited all iterations of the manuscript. Both authors contributed to the ideas herein. 


\section{Literature Cited}

Alroy, J. 1998a. Cope's Rule and the Dynamics of Body Mass Evolution in North American Fossil Mammals. Science 280:731-734.

Alroy, J. 1998b. Equilibrial diversity dynamics in North American mammals. Pages 232-287 in M. McKinney and J. Drake, eds. Biodiversity Dynamics: turnover of populations, taxa, and communities. Columbia University Press, New York.

Anderson, M. J. 2006. Distance-based tests for homogeneity of multivariate dispersions. Biometrics 26:245-253.

Anderson, M. J., K. E. Ellingsen, and B. H. McArdle. 2006. Multivariate dispersion as a measure of beta diversity. Ecology Letters 9:683-693.

Badgley, C. 2010. Tectonics, topography, and mammalian diversity. Ecography 33:220-231.

Bakker, V. J., and D. A. Kelt. 2000. Scale-dependent patterns in body size distributions of Neotropical mammals. Ecology 81:3530-3547.

Bapst, D. W. 2012. paleotree: an R package for paleontological and phylogenetic analyses of evolution. Methods in Ecology and Evolution 3:803-807.

Bapst, D. W. 2013. A stochastic rate-calibrated method for time-scaling phylogenies of fossil taxa. Methods in Ecology and Evolution 4:724-733.

Barnosky, A. D., E. A. Hadly, P. Gonzalez, J. Head, P. D. Polly, A. M. Lawing, J. T. Eronen, D. D. Ackerly, K. Alex, E. Biber, J. Blois, J. Brashares, G. Ceballos, E. Davis, G. P. Dietl, R. Dirzo, H. Doremus, M. Fortelius, H. W. Greene, J. Hellmann, T. Hickler, S. T. Jackson, M. Kemp, P. L. Koch, C. Kremen, E. L. Lindsey, C. Looy, C. R. Marshall, C. Mendenhall, A. Mulch, A. M. Mychajliw, C. Nowak, U. Ramakrishnan, J. Schnitzler, K. Das Shrestha, K. Solari, L. Stegner, M. A. Stegner, N. C. Stenseth, M. H. Wake, and Z. 
Zhang. 2017. Merging paleobiology with conservation biology to guide the future of terrestrial ecosystems. Science 355:eaah4787.

Barnosky, A. D., N. Matzke, S. Tomiya, G. O. U.Wogan, B. Swartz, T. B. Quental, C. Marshall, J. L. McGuire, E. L. Lindsey, K. C. Maguire, B. Mersey, and E. A. Ferrer. 2011. Has the Earth's sixth mass extinction already arrived? Nature 471:51-57.

Baselga, A. 2010. Partitioning the turnover and nestedness components of beta diversity. Global Ecology and Biogeography 19:134-143.

Baselga, A., J. M. Lobo, J.-C. Svenning, P. Aragón, and M. B. Araújo. 2012. Dispersal ability modulates the strength of the latitudinal richness gradient in European beetles. Global Ecology and Biogeography 21:1106-1113.

Benson, R. B. J., R. J. Butler, J. Alroy, P. D. Mannion, M. T. Carrano, and G. T. Lloyd. 2016. Near-Stasis in the Long-Term Diversification of Mesozoic Tetrapods. PLOS Biology 14:e1002359.

Benton, M. J. 1987. Progress and competition in macroevolution. BiologicalReviews 62:305338.

Bowen, G. J. 2014. The Online Isotopes in Precipitation Calculator, version 2.2.

Bowen, G. J., W. C. Clyde, P. L. Koch, S. Ting, J. Alroy, T. Tsubamoto, Y. Wang, and Y. Wang. 2002. Mammalian Dispersal at the Paleocene/Eocene Boundary. Science 295:2062-2065.

Brown, J. H. 1984. On the Relationship between Abundance and Distribution of Species. American Naturalist 124:255-279.

Brown, J. H., and P. F. Nicoletto. 1991. Spatial Scaling of Species Composition: Body Masses of North American Land Mammals. American Naturalist 138:1478-1512. 
Brown, J. H., and D. F. Sax. 2004. An Essay on Some Topics Concerning Invasive Species. Austral Ecology 29:530-536.

Brusatte, S. L., M. J. Benton, M. Ruta, and G. T. Lloyd. 2008. Superiority, Competition, and Opportunism in the Evolutionary Radiation of Dinosaurs. Science 321:1485-1488.

Buckley, L. B., J. Davies, D. D. Ackerly, N. J. B. Kraft, S. P. Harrison, B. L. Anacker, H. V. Cornell, E. I. Damschen, J.-A. Grytnes, B. A. Hawkins, C. M. McCain, P. R. Stephens, and a. J. J. Wiens. 2010. Phylogeny, niche conservatism and the latitudinal diversity gradient in mammals. Proceedings of the Royal Society B 277:2121-2138.

Buckley, L. B., and W. Jetz. 2008. Linking global turnover of species and environments. Proceedings of the National Academy of Sciences of the USA 105:17836-17841.

Burger, B. J. 2012. Northward range extension of a diminutive-sized mammal (Ectocion parvus) and the implication of body size change during the Paleocene-Eocene Thermal Maximum. Palaeogeography, Palaeoclimatology, Palaeoecology 363-364:144-150.

Cadotte, M., C. H. Albert, and S. C. Walker. 2013. The ecology of differences: assessing community assembly with trait and evolutionary distances. Ecology Letters 16:12341244.

Caley, M. J., and D. Schluter. 1997. The Relationship between Local and Regional Diversity. Ecology 78:70-80.

Cavender-Bares, J., D. D. Ackerly, D. A. Baum, and F. A. Bazzaz. 2004. Phylogenetic overdispersion in Floridian oak communities. American Naturalist 163:823-843.

Cavender-Bares, J., A. Keen, and B. Miles. 2006. Phylogenetic Structure of Floridian Plant Communities Depends on Taxonomic and Spatial Scale. Ecology 87:S109-S122. 
Cavender-Bares, J., K. H. Kozak, P. V. A. Fine, and S. W. Kembel. 2009. The merging of community ecology and phylogenetic biology. Ecology Letters 12:693-715.

Chen, I.-C., J. K. Hill, R. Ohlemüller, D. B. Roy, and C. D. Thomas. 2011. Rapid range shifts of species associated with high levels of climate warming. Science 333:1024-1026.

Chesson, P. L., and R. R. Warner. 1981. Environmental Variability Promotes Coexistence in Lottery Competitive Systems. American Naturalist 117:923-943.

Clarke, A., and K. J. Gaston. 2006. Climate, energy and diversity. Proceedings of the Royal Society B 273:2257-2266.

Close, R. A., R. B. Benson, J. Alroy, A. K. Behrensmeyer, J. Benito, M. T. Carrano, T. J. Cleary, E. M. Dunne, P. D. Mannion, and M. D. Uhen. 2019. Diversity dynamics of phanerozoic terrestrial tetrapods at the local-community scale. Nature Ecology \& Evolution 3:590.

Clyde, W. C., and P. D. Gingerich. 1998. Mammalian community response to the latest Paleocene thermal maximum: An isotaphonomic study in the northern Bighorn Basin, Wyoming. Geology 26:1011-1014.

Connor, E. F., and D. Simberloff. 1979. The assembly of species communities: chance or competition? Ecology 60:1132-1140.

Cornell, H. V., and J. H. Lawton. 1992. Species interactions, local and regional processes, and limits to the richness of ecological communities: a theoretical perspective. Journal of Animal Ecology 61:1-12.

Cottenie, K. 2005. Integrating environmental and spatial processes in ecological community dynamics. Ecology Letters 8:1175-1182. 
Darroch, S. A. F., A. E. Webb, N. Longrich, and J. Belmaker. 2014. Palaeocene-Eocene evolution of beta diversity among ungulate mammals in North America. Global Ecology and Biogeography 23:757-768.

Davies, T. J., and L. B. Buckley. 2011. Phylogenetic diversity as a window into the evolutionary and biogeographic histories of present-day richness gradients for mammals. Philosophical Transactions of the Royal Society B 366:2414-2425.

Dayan, T., and D. Simberloff. 1994. Character displacement, sexual dimporphism, and morphological variation among British and Irish mustelids. Ecology 75:1063-1073.

Dayan, T., and D. Simberloff. 1996. Patterns of size separation in carnivore communities. Pages 243-266 in Carnivore behavior, ecology, and evolution.

Dayan, T., and D. J. M. r. Simberloff. 1998. Size patterns among competitors: ecological character displacement and character release in mammals, with special reference to island populations. 28:99-124.

Dietl, G. P., S. M. Kidwell, M. Brenner, D. A. Burney, K. W. Flessa, S. T. Jackson, and P. L. Koch. 2015. Conservation Paleobiology: Leveraging Knowledge of the Past to Inform Conservation and Restoration. Annual Review of Earth and Planetary Sciences 43:79103.

Dobrovolski, R., A. S. Melo, F. A. S. Cassemiro, and J. A. F. Diniz-Filho. 2012. Climatic history and dispersal ability explain the relative importance of turnover and nestedness components of beta diversity. Global Ecology and Biogeography 21:191-197.

Dornelas, M., N. J. Gotelli, B. McGill, H. Shimadzu, F. Moyes, C. Sievers, and A. E. Magurran. 2014. Assemblage time series reveal biodiversity change but not systematic loss. Science 344:296-299. 
Early, R., B. A. Bradley, J. S. Dukes, J. J. Lawler, J. D. Olden, D. M. Blumenthal, P. Gonzalez, E. D. Grosholz, I. Ibanez, L. P. Miller, C. J. B. Sorte, and A. J. Tatem. 2016. Global threats from invasive alien species in the twenty-first century and national response capacities. Nature Communication 7.

Eronen, J. T., P. D. Polly, M. Fred, J. Damuth, D. C. Frank, V. Mosbrugger, C. Scheidegger, N. C. Stenseth, and M. Fortelius. 2010a. Ecometrics: The traits that bind the past and present together. Integrative Zoology 5:88-101.

Eronen, J. T., K. Puolamäki, L. Liu, K. Lintulaakso, J. Damuth, C. Janis, and M. Fortelius. 2010b. Precipitation and large herbivorous mammals I: estimates from present-day communities. Evolutionary Ecology Research 12:217-233.

Faurby, S., and J.-C. Svenning. 2015. Historic and prehistoric human-driven extinctions have reshaped global mammal diversity patterns. Diversity and Distributions:1-12.

Faurby, S., and J.-C. Svenning. 2016. The asymmetry in the Great American Biotic Interchange in mammals is consistent with differential susceptibility to mammalian predation. Global Ecology and Biogeography 25:1443-1453.

Finarelli, J. A., and C. Badgley. 2010. Diversity dynamics of Miocene mammals in relation to the history of tectonism and climate. Proceedings of the Royal Society B 277:2721-2726.

Fraser, D., R. Gorelick, and N. Rybczynski. 2015. Macroevolution and climate change influence phylogenetic community assembly of North American hoofed mammals. Biological Journal of the Linnean Society 114:485-494.

Fraser, D., C. Hassall, R. Gorelick, and N. Rybczynski. 2014. Mean annual precipitation explains spatiotemporal patterns of Cenozoic mammal beta diversity and latitudinal diversity gradients in North America. PLoS One 9:e106499. 
Fraser, D., R. J. Haupt, and W. A. Barr. 2018. Phylogenetic signal in tooth wear dietary niche proxies. Ecology and Evolution.

Fraser, D., and S. K. Lyons. 2017. Biotic interchange has structured Western Hemisphere mammal communities. Global Ecology and Biogeography 26:1408-1422.

Freckleton, R. P., P. H. Harvey, and M. Pagel. 2003. Bergmann's rule and body size in mammals. American Naturalist 161:821-825.

Freilich, M. A., and S. R. Connolly. 2015. Phylogenetic community structure when competition and environmental filtering determine abundances. Global Ecology and Biogeography 24:1390-1400.

Fridley, J. D., J. J. Stachowicz, S. Naeem, D. F. Sax, E. W. Seabloom, M. D. Smith, T. J. Stohlgren, D. Tilman, and B. Von Holle. 2007. The invasion paradox: Reconciling pattern and process in species invasions. Ecology 88:3-17.

Fritz, S. A., O. R. P. Bininda-Emonds, and A. Purvis. 2009. Geographical variation in predictors of mammalian extinction risk: big is bad, but only in the tropics. Ecology Letters 12:538549.

Fritz, S. A., and A. Purvis. 2010. Phylogenetic diversity does not capture body size variation at risk in the world's mammals. Proceedings of the Royal Society B 277:2435-2441.

Gill, D. E. 1974. Intrinsic Rate of Increase, Saturation Density, and Competitive Ability. II. The Evolution of Competitive Ability. American Naturalist 108:103-116.

Gingerich, P. D. 1989. New earliest Wasatchian mammalian fauna from the Eocene of northwestern Wyoming: composition and diversity in a rarely sampled high-floodplain assemblage. University of Michigan Papers on Paleontology 28:1-97. 
Gingerich, P. D. 2001. Biostratigraphy of the continental Paleocene- Eocene boundary interval on Polecat Bench in the northern Bighorn Basin. Pages 37-71 in P. D. Gingerich, ed. Paleocene-Eocene Stratigraphy and Biotic Change in the Bighorn and Clarks Fork Basins, Wyoming.

Gingerich, P. D. 2003. Mammalian responses to climate change at the Paleocene-Eocene boundary: Polecat Bench record in the northern Bighorn Basin, Wyoming. Pages 463-478 in S. Wing, P. Gingerich, B. Schmitz, and E. Thomas, eds. Causes and consequences of globally warm climates in the Early Paleogene. Geological Society of America, Boulder, CO.

Gingerich, P. D. 2006. Environment and evolution through the Paleocene-Eocene thermal maximum. Trends in Ecology \& Evolution 21:246-253.

Gingerich, P. D., K. D. Rose, and D. W. Krause. 1980. Early Cenozoic mammalian faunas of the Clark's Fork Basin-Polecat Bench area, northwestern Wyoming. University of Michigan Papers on Paleontology 24:51-68.

Gotelli, N. J. 2000. Null model analysis of species co-occurrence patterns. Ecologv 81:26062621.

Gotelli, N. J., and G. L. Entsminger. 2001. Swap and fill algorithms in null model analysis: rethinking the knight's tour. Oecologia 129:281-291.

Gotelli, N. J., and R. K.Colwell. 2011. Estimating species richness. Pages 39-54 in A. Magurran and B. McGill, eds. Frontiers in Measuring Biodiversity. Oxford University Press, New York.

Gould, S. J., and C. B. Calloway. 1980. Clams and brachiopods-ships that pass in the night. Paleobiology 6:383-396. 
Graham, C. H., and P. V. A. Fine. 2008. Phylogenetic beta diversity: linking ecological and evolutionary processes across space in time. Ecology Letters 1265-1277.

Halliday, T. J. D., P. Upchurch, and A. Goswami. 2015. Resolving the relationships of Paleocene placental mammals. Biological Reviews.

Hardin, G. 1960. The competitive exclusion principle. Science 131:1292-1297.

Hardy, O. J. 2008. Testing the spatial phylogenetic structure of local communities: statistical performances of different null models and test statistics on a locally neutral community. Journal of Ecology 96:914-926.

Heltshe, J. F., and N. E. Forrester. 1983. Estimating Species Richness Using the Jackknife Procedure. Biometrics 39:1-11.

Huang, S., T. J. Davies, and J. L. Gittleman. 2011. How global extinctions impact regional biodiversity in mammals. Biology Letters:1-4.

Hurlbert, A. H., and W. Jetz. 2007. Species richness, hotspots, and the scale dependence of range maps in ecology and conservation. Proceedings of the National Academy of Sciences of the USA 104:13384-13389.

Jackson, S. T., and D. F. Sax. 2010. Balancing biodiversity in a changing environment: extinction debt, immigration credit and species turnover. Trends in Ecology \& Evolution 25:153-160.

Janis, C. M., G. F. Gunnell, and M. D. Uhen. 2008. Evolution of the Tertiary mammals of North America: Small mammals, xenarthrans, and marine mammals. Cambridge University Press, Cambridge. 
Janis, C. M., K. M. Scott, and L. L. Jacobs. 1998. Evolution of the Tertiary mammals of North America: Terrestrial carnivores, ungulates, and ungulatelike mammals. Cambridge University Press, Cambridge.

Jones, K. E., J. Bielby, M. Cardillo, S. A. Fritz, J. O'Dell, C. D. L. Orme, K. Safi, W. Sechrest, E. H. Boakes, C. Carbone, C. Connolly, M. J. Cutts, J. K. Foster, R. Grenyer, M. Habib, C. A. Plaster, S. A. Price, E. A. Rigby, J. Rist, A. Teacher, O. R. P. Bininda-Emonds, J. L. Gittleman, G. M. Mace, and A. Purvis. 2009. PanTHERIA: a species-level database of life history, ecology, and geography of extant and recently extinct mammals. Ecology 90:2648.

Kelt, D. A., and M. D. Meyer. 2009. Body size frequency distributions in African mammals are bimodal at all spatial scales. Global Ecology and Biogeography 18:19-29.

Kelt, D. A., and D. Van Vuren. 1999. Energetic constraints and the relationship between body size and home range area in mammals. Ecology 80:337-340.

Kembel, S. W. 2009. Disentangling niche and neutral influences on community assembly: assessing the performance of community phylogenetic structure tests. Ecology Letters 12:949-960.

Kembel, S. W., D. D. Ackerly, S. Blomberg, W. K. Cornwell, P. D. Cowan, M. R. Helmus, H. Morlon, and C. O. Webb. 2014. R tools for integrating phylogenies and ecology.

Kembel, S. W., and S. P. Hubbell. 2006. The phylogenetic structure of a neotropical forest tree community. Ecology 87:S86-S99.

Kerfoot, W. C., and L. J. Weider. 2004. Experimental paleoecology (resurrection ecology): Chasing Van Valen's Red Queen hypothesis. Limnology and Oceanography 49:13001316. 
Kerr, J. T., A. Pindar, P. Galpern, L. Packer, S. G. Potts, S. M. Roberts, P. Rasmont, O. Schweiger, S. R. Colla, L. L. Richardson, D. L. Wagner, L. F. Gall, D. S. Sikes, and A. Pantoja. 2015. Climate change impacts on bumblebees converge across continents. Science 349:177-180.

Kraft, N. J. B., P. B. Adler, O. Godoy, E. C. James, S. Fuller, and J. M. Levine. 2015. Community assembly, coexistence and the environmental filtering metaphor. Functional Ecology 29:592-599.

Kraft, N. J. B., L. S. Comita, J. M. Chase, N. J. Sanders, N. G. Swenson, T. O. Crist, J. C. Stegen, M. Vellend, B. Boyle, M. J. Anderson, H. V. Cornell, K. F. Davies, A. L. Freestone, B. D. Inouye, S. P. Harrison, and J. A. Myers. 2011. Disentangling the drivers of $\beta$ diversity along latitudinal and elevational gradients. Science 333:1755-1758.

Laake, J. L. 2013. RMark: an R interface for analysis of capture-recapture data with MARK.

Lamanna, C., B. Blonder, C. Violle, N. J. B. Kraft, B. Sandel, I. Šímová, J. C. D. II, J.-C. Svenning, B. J. McGill, B. Boyle, V. Buzzard, S. Dolins, P. M. Jørgensen, A. MarcuseKubitza, N. Morueta-Holme, R. K. Peet, W. H. Piel, J. Regetz, M. Schildhauer, N. Spencer, B. Thiers, S. K. Wiser, and B. J. Enquist. 2014. Functional trait space and the latitudinal diversity gradient. Proceedings of the National Academy of Sciences of the USA 111:13745-13750.

Laurin, M. 2004. The evolution of body size, Cope's Rule and the origin of amniotes. Systematic Biology 53:594-622.

Lawing, A. M., J. T. Eronen, J. L. Blois, C. H. Graham, and P. D. Polly. 2017. Community functional trait composition at the continental scale: the effects of non-ecological processes. Ecography 40:651-663. 
Leibold, M. A., M. Holyoak, N. Mouquet, P. Amarasekare, J. M. Chase, M. F. Hoopes, R. D. Holt, J. B. Shurin, R. Law, D. Tilman, M. Loreau, and A. Gonzalez. 2004. The metacommunity concept: a framework for multi-scale community ecology. Ecology Letters 7:601-613.

Liow, L. H., and J. D. Nichols. 2010. Estimating rates and probabilities of origination and extinction using taxonomic occurrence data: capture-mark-recapture (CMR) approaches. The Paleontological Society Papers 16:81-94.

Liow, L. H., T. Reitan, and P. G. Harnik. 2015. Ecological interactions on macroevolutionary time scales: clams and brachiopods are more than ships that pass in the night. Ecology Letters 18:1030-1039.

Liow, L. H., and N. C. Stenseth. 2007. The rise and fall of species: implications for macroevolutionary and macroecological studies. Proceedings of the Royal Society B 274:2745-2752.

Lloyd, G. T., S. C. Wang, and S. L. Brusatte. 2012. Identifying heterogeneity in rates of morphological evolution: discrete character change in the evolution of lungfish (Sarcopterygii; Dipnoi). Evolution 66:330-348.

Longman, E. K., K. Rosenblad, and D. F. Sax. 2018. Extreme homogenization: The past, present and future of mammal assemblages on islands. Global Ecology and Biogeography 27:7795.

Losos, J. B. 2008. Phylogenetic niche conservatism, phylogenetic signal and the relationship between phylogenetic relatedness and ecological similarity among species. Ecology Letters 11:995-1007. 
Lyons, S. K., K. L. Amatangelo, A. K. Behrensmeyer, A. Bercovici, J. L. Blois, M. Davis, W. A. DiMichele, A. Du, J. T. Eronen, J. Tyler Faith, G. R. Graves, N. Jud, C. Labandeira, C. V. Looy, B. McGill, J. H. Miller, D. Patterson, S. Pineda-Munoz, R. Potts, B. Riddle, R. Terry, A. TÃ $\tilde{3}^{3}$ th, W. Ulrich, A. Villase Ã \pm or, S. Wing, H. Anderson, J. Anderson, D. Waller, and N. J. Gotelli. 2016a. Holocene shifts in the assembly of plant and animal communities implicate human impacts. Nature 529:80-83.

Lyons, S. K., J. H. Miller, D. Fraser, F. A. Smith, A. Boyer, E. Lindsey, and A. M. Mychajliw. 2016b. The changing role of mammal life histories in Late Quaternary extinction vulnerability on continents and islands. Biology Letters 12: 20160342.

Lyons, S. K., and F. A. Smith. 2013. Macroecological patterns of body size in mammals across time and space. Pages _ _ in F. A. Smith and S. K. Lyons, eds. Animal body size: linking pattern and process across space, time, and taxonomic group. University of Chicago Press, Chicago.

MacArthur, R., and R. Levins. 1967. The limiting similarity, convergence and divergence of coexisting species. American Naturalist 101:377-385.

Magurran, A. E., M. Dornelas, F. Moyes, N. J. Gotelli, and B. McGill. 2015. Rapid biotic homogenization of marine fish assemblages. Nature Communications 6:1-5.

Mayfield, M. M., and J. M. Levine. 2010. Opposing effects of competitive exclusion on the phylogenetic structure of communities. Ecology Letters 13:1085-1093.

Mazel, F., R. O. Wüest, M. Gueguen, J. Renaud, G. F. Ficetola, S. Lavergne, and W. Thuiller. 2017. The Geography of Ecological Niche Evolution in Mammals. Current Biology $27: 1369-1374$. 
McCreless, E. E., D. D. Huff, D. A. Croll, B. R. Tershy, D. R. Spatz, N. D. Holmes, S. H. M. Butchart, and C. Wilcox. 2016. Past and estimated future impact of invasive alien mammals on insular threatened vertebrate populations. Nature Communications 7:1-11.

McInerney, F. A., and S. L. Wing. 2011. The Paleocene-Eocene Thermal Maximum: A perturbation of carbon cycle, climate, and biosphere with implications for the future. Annual Review of Earth and Planetary Sciences 39:489-516.

McKinney, M. L., and J. L. Lockwood. 1999. Biotic homogenization: a few winners replacing many losers in the next mass extinction. Trends in Ecology \& Evolution 14:450-453.

McNab, B. K. 1979. The influence of body size on the energetics and distribution of fossorial and burrowing mammals. Ecology 60:1010-1021.

McNab, B. K. 1989. Basal rate of metabolism, body size, and food habits in the order Carnivora. Pages 335-354 in Carnivore behavior, ecology, and evolution. Springer.

Moen, D., and H. Morlon. 2014. Why does diversification slow down? Trends in Ecology \& Evolution 29:190-197.

Myers, N., and A. H. Knoll. 2001. The biotic crisis and the future of evolution. Proceedings of the National Academy of Sciences of the USA 98:5389-5392.

Oksanen, J., F. G. Blanchet, P. L. Roeland Kindt, P. R. Minchin, R. B. O'Hara, G. L. Simpson, P. Solymos, M. H. H. Stevens, and H. Wagner. 2012. Package vegan version 2.0-7.

Olden, J. D., N. LeRoy Poff, M. R. Douglas, M. E. Douglas, and K. D. Fausch. 2004. Ecological and evolutionary consequences of biotic homogenization. Trends in Ecology \& Evolution 19:18-24. 
Oliveira, B. F., A. Machac, G. C. Costa, T. M. Brooks, A. D. Davidson, C. Rondinini, and C. H. Graham. 2016. Species and functional diversity accumulate differently in mammals. Global Ecology and Biogeography:1466-8238.

Parmesan, C. 2006. Ecological and evolutionary responses to recent climate change. Annual Review of Ecology and Systematics 37:637-639.

Parmesan, C., and G. Yohe. 2003. A globally coherent fingerprint of climate change impacts across natural systems. Nature 421:37-42.

Patterson, B. D., G. Ceballos, W. Sechrest, M. F. Tognelli, T. Brooks, L. Luna, P. Ortega, I. Salazar, and B. E. Young. 2007. Digital distribution maps of the mammals of the Western Hemisphere, version 3.0. NatureServe, Arlington, Virginia, USA.

Pavoine, S., and M. B. Bonsall. 2010. Measuring biodiversity to explain community assembly: a unified approach. Biological Reviews 86: 792-812.

Peters, R. H. 1983. The ecological implications of body size. Cambridge University Press, New York.

Pineda-Munoz, S., A. R. Evans, and J. Alroy. 2016. The relationship between diet and body mass in terrestrial mammals. Paleobiology 42:1-11.

Polly, P. D. 2010. Tiptoeing through the trophics: geographic variation in carnivoran locomotor ecomorphology in relation to environment. Pages 374-401 in Carnivoran evolution: new views on phylogeny, form, and function.

Polly, P. D., J. T. Eronen, M. Fred, G. P. Dietl, V. Mosbrugger, C. Scheidegger, D. C. Frank, J. Damuth, N. C. Stenseth, and M. Fortelius. 2011. History matters: ecometrics and integrative climate change biology. Proceedings of the Royal Society B 278:1131-1140. 
Polly, P. D., J. Fuentes-Gonzalez, A. M. Lawing, A. K. Bormet, and R. G. Dundas. 2017. Clade sorting has a greater effect than local adaptation on ecometric patterns in Carnivora. Evolutionary Ecology Research 18:61-95.

Price, P. W. 1984. Communities of specialists: vacant niches in ecological and evolutionary time. Pages 510-523 in D. R. Strong Jr, D. Simberloff, L. G. Abele, and A. B. Thistle, eds. Ecological Communities: Conceptual Issues and the Evidence. Princeton University Press, Princeton.

Qian, H., C. Badgley, and D. L. Fox. 2009. The latitudinal gradient of beta diversity in relation to climate and topography for mammals in North America. Global Ecology and Biogeography 18:111-122.

Qian, H., and R. E. Ricklefs. 2006. The role of exotic species in homogenizing the North American flora. Ecology Letters 9:1293-1298.

Qian, H., and M. Xiao. 2012. Global patterns of the beta diversity energy relationship in terrestrial vertebrates. Acta Oecologica 39:67-71.

Qian, H., Y. Zhang, J. Zhang, and X. Wang. 2013. Latitudinal gradients in phylogenetic relatedness of angiosperm trees in North America. Global Ecology and Biogeography 22:1183-1191.

Raia, P. 2010. Phylogenetic community assembly over time in Eurasian Plio-Pleistocene Mammals. PALAIOS 25:327-338.

Raia, P., C. Meloro, A. Loy, and C. Barbera. 2006. Species occupancy and its course in the past: macroecological patterns in extinct communities. Evolutionary Ecology Research 8:181194. 
Rankin, B. D., J. W. Fox, C. R. Barrón-Ortiz, A. E. Chew, P. A. Holroyd, J. A. Ludtke, X. Yang, and J. M. Theodor. 2015. The extended Price equation quantifies species selection on mammalian body size across the Palaeocene/Eocene Thermal Maximum. Proceedings of the Royal Society B 282:20151097.

Razafindratsima, O. H., S. Mehtani, and A. E. Dunham. 2012. Extinctions, traits and phylogenetic community structure: insights from primate assemblages in Madagascar. Ecography 35:1-10.

Ricciardi, A. 2007. Are Modern Biological Invasions an Unprecedented Form of Global Change? ¿Las Invasiones Biológicas Modernas son una Forma de Cambio Global sin Precedente? Conservation Biology 21:329-336.

Ricklefs, R. E. 2010. Evolutionary diversification, coevolution between populations and their antagonists, and the filling of niche space. Proceedings of the National Academy of Sciences of the USA 107: 1265-1272. :1-8.

Roopnarine, P. D., and K. D. Angielczyk. 2015. Community stability and selective extinction during the Permian-Triassic mass extinction. Science 350:90-93.

Rosenzweig, M. L. 1995. Species diversity in space and time. Cambridge University Press, Cambridge.

Rowan, J., J. M. Kamilar, L. Beaudrot, and K. E. Reed. 2016. Strong influence of palaeoclimate on the structure of modern African mammal communities. Proceedings of the Royal Society B 283: 20161207.

Safi, K., M. V. Cianciaruso, R. D. Loyola, D. Brito, K. Armour-Marshall, and J. A. F. DinizFilho. 2011. Understanding global patterns of mammalian functional and phylogenetic diversity. Philosophical Transactions of the Royal Society B 366:2536-2544. 
Sax, D. F., and J. H. Brown. 2000. The paradox of invasion. Global Ecology and Biogeography 9:363-371.

Sax, D. F., and S. D. Gaines. 2008. Species invasions and extinction: the future of native biodiversity on islands. Proceedings of the National Academy of Sciences of the USA 105:11490-11497.

Sax, D. F., S. D. Gaines, and J. H. Brown. 2002. Species invasions exceed extinctions on islands worldwide: A comparative study of plants and birds. American Naturalist 160:766-783.

Schoener, T. W. 1974. Resource Partitioning in Ecological Communities. Science 185:27-39.

Secord, R., J. I. Bloch, S. G. B. Chester, D. M. Boyer, A. R. Wood, S. L. Wing, M. J. Kraus, F. A. McInerney, and J. Krigbaum. 2012. Evolution of the earliest horses driven by climate change in the Paleocene-Eocene thermal maximum. Science 335:959-962.

Secord, R., P. D. Gingerich, M. E. Smith, W. C. Clyde, P. Wilf, and B. S. Singer. 2006. Geochronology and mammalian biostratigraphy of middle and upper Paleocene continental strata, Bighorn Basin, Wyoming. American Journal of Science 306:211-245.

Secord, R., S. L. Wing, and A. Chew. 2008. Stable isotopes in early Eocene mammals as indicators of forest canopy structure and resource partitioning. Paleobiology 34:282-300.

Seebens, H., T. M. Blackburn, E. E. Dyer, P. Genovesi, P. E. Hulme, J. M. Jeschke, S. Pagad, P. Pyšek, M. Winter, and M. Arianoutsou. 2017. No saturation in the accumulation of alien species worldwide. Nature Communications 8:14435.

Simpson, G. G. 1947. Holarctic mammal faunas and continental relationships during the Cenozoic. Geological Society of America Bulletin 58:613-688.

Smith, E. P., and G. v. Belle. 1984. Nonparametric Estimation of Species Richness. Biometrics 40:119-129. 
Smith, F. A., J. H. Brown, J. P. Haskell, S. K. Lyons, J. Alroy, E. L. Charnov, T. Dayan, B. J. Enquist, S. K. Morgan Ernest, E. A. Hadly, and K. E. Jones. 2004. Similarity of Mammalian Body Size across the Taxonomic Hierarchy and across Space and Time. American Naturalist 163:672-691.

Smith, F. A., A. G. Boyer, J. H. Brown, D. P. Costa, T. Dayan, S. K. M. Ernest, A. R. Evans, M. Fortelius, J. L. Gittleman, M. J. Hamilton, L. E. Harding, K. Lintulaakso, S. K. Lyons, C. McCain, J. G. Okie, J. J. Saarinen, R. M. Sibly, P. R. Stephens, J. Theodor, and M. D. Uhen. 2010. The evolution of maximum body size of terrestrial mammals. Science 330:1216-1219.

Smith, F. A., and S. K. Lyons. 2013. Animal body size: linking pattern and process across space, time, and taxonomic group. University of Chicago Press, Chicago IL.

Smith, F. A., R. E. E. Smith, S. K. Lyons, and J. L. Payne. 2018. Body size downgrading of mammals over the late Quaternary. Science 360:310-313.

Smits, P. D. 2015. Expected time-invariant effects of biological traits on mammal species duration. Proceedings of the National Academy of Sciences of the USA 112:1301513020.

Soininen, J. 2010. Species turnover along abiotic and biotic gradients: patterns in space equal patterns in time? BioScience 60:433-439.

Soininen, J., J. J. Lennon, and H. Hillebrad. 2007a. A multivariate analysis of beta diversity across organisms and environments. Ecology 88:2830-2838.

Soininen, J., R. McDonald, and H. Hillebrand. 2007b. The distance decay of similarity in ecological communities. Ecography 30:3-12. 
Soul, L. C., and M. Friedman. 2015. Taxonomy and Phylogeny Can Yield Comparable Results in Comparative Paleontological Analyses. Systematic Biology 64:608-620.

Stroik, L. K., and G. T. Schwartz. 2018. The role of dietary competition in the origination and early diversification of North American euprimates. Proceedings of the Royal Society B 285:20181230.

Swenson, N. G. 2011. Phylogenetic Beta Diversity Metrics, Trait Evolution and Inferring the Functional Beta Diversity of Communities. PloS One 6:1-9.

Tarver, J. E., M. dos Reis, S. Mirarab, R. J. Moran, S. Parker, J. E. O'Reilly, B. L. King, M. J. O'Connell, R. J. Asher, T. Warnow, K. J. Peterson, P. C. J. Donoghue, and D. Pisani. 2016. The Interrelationships of Placental Mammals and the Limits of Phylogenetic Inference. Genome Biology and Evolution.

Tomiya, S. 2013. Body Size and Extinction Risk in Terrestrial Mammals Above the Species Level. American Naturalist 182:E196-E214.

Tóth, A. B., S. K. Lyons, W. A. Barr, A. K. Behrensmeyer, J. L. Blois, R. Bobe, M. Davis, A. Du, J. T. Eronen, J. T. Faith, D. Fraser, N. J. Gotelli, G. R. Graves, A. M. Jukar, J. H. Miller, S. Pineda-Munoz, L. C. Soul, A. Villaseñor, and J. Alroy. 2019. Reorganization of surviving mammal communities after the end-Pleistocene megafaunal extinction. Science 365:1305-1308.

Toth, A. B., S. K. Lyons, and A. K. Behrensmeyer. 2014. A Century of Change in Kenya's Mammal Communities: Increased Richness and Decreased Uniqueness in Six Protected Areas. PLos One 9.

Tóth, A. B., S. K. Lyons, and A. K. Behrensmeyer. 2014. Mammals of Kenya's protected areas from 1888 to 2013: Ecological Archives E095-150. Ecology 95:1711-1711. 
Tucker, C. M., T. J. Davies, M. W. Cadotte, and W. D. Pearse. 2018. On the relationship between phylogenetic diversity and trait diversity. Ecology 99: 1473-1479.

Turner, J. R. G. 2004. Explaining the global biodiversity gradient: energy, area, history and natural selection. Basic and Applied Ecology 5:435-448.

Ulrich, W., and N. J. Gotelli. 2007a. Disentangling community patterns of nestedness and species co-occurrence. Oikos 116:2053-2061.

Ulrich, W., and N. J. Gotelli. 2007b. Null model analysis of species nestedness patterns. Ecology 88:1824-1831.

Ulrich, W., Y. Kubota, B. Kusumoto, A. Baselga, H. Tuomisto, and N. J. Gotelli. 2018. Species richness correlates of raw and standardized co-occurrence metrics. Global Ecology and Biogeography 27:395-399.

Vamosi, S. M., S. B. Heard, J. C. Vamosi, and C. O. Webb. 2009. Emerging patterns in the comparative analysis of phylogenetic community structure. Molecular Ecology 18:572592.

Vavrek, M. J. 2012. Palaeoecological and Palaeogeographical Analysis Tools.

Vermeij, G. J. 1991. When biotas meet: understanding biotic interchange. Science 253:10991104.

Vermeij, G. J. 2005. Invasion as expectation. Pages 315-339 in D. F. Sax, J. J. Stachowicz, and S. D. Gaines, editors. Species invasions: insight into ecology, evolution and biogeography. Sinauer Associates, Sunderland, MA.

Vitousek, P. M., C. M. D'Antonio, L. L. Loope, M. Rejmánek, and R. Westbrooks. 1997. Introduced species: a significant component of human-caused global change. New Zealand Journal of Ecology 21:1-16. 
Vitousek, P. M., C. M. D’Antonio, L. L. Loope, and R. Westbrooks. 1996. Biological invasions as global environmental change. American Scientist 84:468-478.

Walker, T. D., and J. W. Valentine. 1984. Equilibrium models of evolutionary species diversity and the number of empty niches. American Naturalist 124:887-899.

Walther, B. A., and S. Morand. 1998. Comparative performance of species richness estimation methods. Parasitology 116:395-405.

Webb, C. O. 2000. Exploring the phylogenetic structure of ecological communities: an example for rain forest trees. American Naturalist 156:145-155.

Webb, C. O., D. D. Ackerly, M. A. McPeek, and M. J. Donoghue. 2002. Phylogenies and community ecology. Annual Review of Ecology and Systematics 33:475-505.

Webb, C. O., and M. J. Donaghue. 2005. Phylomatic: tree assembly for applied phylogenetics. Molecular Ecology Notes 5:181-183.

White, G. C., and K. P. Burnham. 1999. Program MARK: survival estimation from populations of marked animals. Bird Study 46:S120-S139.

Whittaker, R. J., K. J. Willis, and R. Field. 2001. Scale and species richness: towards a general, hierarchical theory of species diversity. Journal of Biogeography 28:453-470.

Wiens, J. J., and C. H. Graham. 2005. Niche conservatism: integration evolution, ecology, and conservation biology. Annual Review in Ecology, Evolution, and Systematics 36:519539.

Wing, S. L. 2000. Cool, warm, cool, warm — climate oscillation and floral change during the Paleocene/Eocene boundary interval. GFF 122:182-183. 
Wing, S. L., G. J. Harrington, F. A. Smith, J. I. Bloch, D. M. Boyer, and K. H. Freeman. 2005. Transient Floral Change and Rapid Global Warming at the Paleocene-Eocene Boundary. Science 310:993-996.

Woodburne, M. O. 2010. The Great American Biotic Interchange: dispersals, tectonics, climate, sea level and holding pens. Journal of Mammalian Evolution 17:245-264.

Woodburne, M. O., G. F. Gunnell, and R. K. Stucky. 2009. Climate directly influences Eocene mammal faunal dynamics in North America. Proceedings of the National Academy of Sciences of the USA 106:13399-13403.

Zachos, J., M. Pagani, L. Sloan, E. Thomas, and K. Billups. 2001. Trends, rhythms, and aberrations in global climate 65 Ma to present. Science 292:686-693.

Zachos, J. C., G. R. Dickens, and R. E. Zeebe. 2008. An early Cenozoic perspective on greenhouse warming and carbon-cycle dynamics. Nature 451:279-283.

Žliobaitè, I., M. Fortelius, and N. C. Stenseth. 2017. Reconciling taxon senescence with the Red Queen's hypothesis. Nature. 


\section{TABLES}

TABLE 1. Model fit statistics from the Pradel Seniority capture-recapture models.

\begin{tabular}{|c|c|c|c|c|c|}
\hline Model & $\mathrm{N}$ parameters & $\mathrm{AICc}$ & $\triangle \mathrm{AICc}$ & $\begin{array}{l}\text { Akaike } \\
\text { Weight }\end{array}$ & Deviance \\
\hline extinction $(\sim 1)+\operatorname{sampling}(\sim$ time $)+\operatorname{origination}(\sim$ time $)$ & 12 & 877.16 & 0.00 & 0.62 & 45.59 \\
\hline extinction $(\sim$ time $)+\operatorname{sampling}(\sim$ time $)+$ origination $(\sim$ time $)$ & 16 & 878.18 & 1.01 & 0.38 & 37.64 \\
\hline extinction $(\sim$ time $)+\operatorname{sampling}(\sim 1)+$ origination $(\sim$ time $)$ & 11 & 893.17 & 16.01 & 0.00 & 63.80 \\
\hline extinction $(\sim 1)+\operatorname{sampling}(\sim$ time $)+$ origination $(\sim 1)$ & 8 & 897.41 & 20.25 & 0.00 & 74.52 \\
\hline extinction $(\sim 1)+\operatorname{sampling}(\sim 1)+$ origination $(\sim$ time $)$ & 7 & 902.79 & 25.62 & 0.00 & 82.03 \\
\hline extinction $(\sim$ time $)+\operatorname{sampling}(\sim$ time $)+$ origination $(\sim 1)$ & 12 & 904.32 & 27.16 & 0.00 & 72.75 \\
\hline extinction $(\sim$ time $)+$ sampling $(\sim 1)+$ origination $(\sim 1)$ & 7 & 913.44 & 36.27 & 0.00 & 92.68 \\
\hline extinction $(\sim 1)+\operatorname{sampling}(\sim 1)+$ origination $(\sim 1)$ & 3 & 914.62 & 37.46 & 0.00 & 102.21 \\
\hline
\end{tabular}

Extinction refers to last appearances due to extinction or extirpation from the Bighorn Basin.

Origination refers to first appearances due to speciation or invasion. $\sim 1$ denotes time constant while time denotes time variable model terms. 
Table 2. Results of Kolmorgorov-Smirnov tests comparing the body size distributions of each time interval.

\begin{tabular}{|c|c|c|c|c|c|c|}
\hline & Tiffanian 6 & Clarkfork 1 & Clarkfork 2 & Clarkfork 3 & Wasatch 0 & Wasatch 1-2 \\
\hline Tiffanian 6 & & $\begin{array}{l}D=0.494 \\
p=0.008\end{array}$ & $\begin{array}{l}\mathrm{D}=0.307 \\
\mathrm{p}=0.060\end{array}$ & $\begin{array}{l}\mathrm{D}=0.423 \\
\mathrm{p}=0003\end{array}$ & $\begin{array}{l}D=0.376 \\
p=0.006\end{array}$ & $\begin{array}{l}D=0.403 \\
p=0.002\end{array}$ \\
\hline Clarkfork 1 & & & $\begin{array}{l}D=0.242 \\
p=0.473\end{array}$ & $\begin{array}{l}D=0.169 \\
p=0.881\end{array}$ & $\begin{array}{l}D=0.202 \\
p=0.664\end{array}$ & $\begin{array}{l}\mathrm{D}=0.248 \\
\mathrm{p}=0.380\end{array}$ \\
\hline Clarkfork 2 & & & & $\begin{array}{l}\mathrm{D}=0.161 \\
\mathrm{p}=0.652\end{array}$ & $\begin{array}{l}D=0.110 \\
p=0.934\end{array}$ & $\begin{array}{l}D=0.153 \\
p=0.584\end{array}$ \\
\hline Clarkfork 3 & & & & & $\begin{array}{l}D=0.127 \\
p=0.844\end{array}$ & $\begin{array}{l}D=0.128 \\
p=0.967\end{array}$ \\
\hline Wasatch 0 & & & & & & $\begin{array}{l}D=0.091 \\
p=0.967\end{array}$ \\
\hline
\end{tabular}

$\mathrm{D}=$ Kolmorgorov-Smirnov test statistic, $\mathrm{p}=\mathrm{p}$ value. A Bonferroni correction was applied for multiple comparisons giving an $\alpha \leq 0.002$ for significance. Significant comparisons are in bold. 
Table 3. Standardized differences of observed values between successive North American Land

Mammal Ages for all community assembly metrics calculated using Cohen's D.

\begin{tabular}{|c|c|c|c|c|c|}
\hline Metric & NALMAs & Mean Change & Effect Size & Upper $95 \%$ CI & Lower $95 \% \mathrm{CI}$ \\
\hline \multirow[t]{5}{*}{ NRI } & Tiffanian 6 - Clarkfork 1 & -0.44 & -0.35 & -4.69 & 3.98 \\
\hline & Clarkfork 1 - Clarkfork 2 & 0.30 & 0.32 & -1.17 & 1.81 \\
\hline & Clarkfork 2 - Clarkfork 3 & -0.28 & -0.29 & -0.84 & 0.26 \\
\hline & Clarkfork 3 - Wasatch 0 & 1.19 & 1.44 & 0.76 & 2.12 \\
\hline & Wasatch 0 - Wasatch $1 / 2$ & -0.48 & -0.73 & -1.47 & 0.01 \\
\hline \multirow[t]{5}{*}{ NTI } & Tiffanian 6 - Clarkfork 1 & -0.95 & -0.50 & -4.87 & 3.87 \\
\hline & Clarkfork 1 - Clarkfork 2 & -0.09 & -0.09 & -1.68 & 1.50 \\
\hline & Clarkfork 2 - Clarkfork 3 & -0.21 & -0.23 & -0.89 & 0.43 \\
\hline & Clarkfork 3 - Wasatch 0 & 0.82 & 0.88 & 0.25 & 1.52 \\
\hline & Wasatch 0 - Wasatch $1 / 2$ & -0.14 & -0.13 & -0.85 & 0.59 \\
\hline \multirow[t]{5}{*}{$\mathrm{BM}_{\text {dist }}$} & Tiffanian 6 - Clarkfork 1 & -0.31 & -2.68 & -8.61 & 3.25 \\
\hline & Clarkfork 1 - Clarkfork 2 & 0.63 & 1.03 & -0.60 & 2.66 \\
\hline & Clarkfork 2 - Clarkfork 3 & -0.19 & -0.40 & -1.07 & 0.27 \\
\hline & Clarkfork 3 - Wasatch 0 & -0.34 & -0.75 & -1.38 & -0.12 \\
\hline & Wasatch 0 - Wasatch $1 / 2$ & 0.19 & 0.37 & -0.36 & 1.09 \\
\hline \multirow[t]{5}{*}{$\beta$ diversity } & Tiffanian 6 - Clarkfork 1 & -0.08 & -0.68 & -2.02 & 0.65 \\
\hline & Clarkfork 1 - Clarkfork 2 & 0.05 & 0.47 & -0.14 & 1.08 \\
\hline & Clarkfork 2 - Clarkfork 3 & -0.01 & -0.12 & -0.55 & 0.31 \\
\hline & Clarkfork 3 - Wasatch 0 & 0.08 & 0.82 & 0.40 & 1.23 \\
\hline & Wasatch 0 - Wasatch $1 / 2$ & -0.02 & -0.19 & -0.71 & 0.32 \\
\hline \multirow[t]{5}{*}{ NRI } & Tiffanian 6 - Clarkfork 1 & -0.44 & -0.35 & -4.69 & 3.98 \\
\hline & Clarkfork 1 - Clarkfork 2 & 0.30 & 0.31 & -1.28 & 1.91 \\
\hline & Clarkfork 2 - Clarkfork 3 & -0.28 & -0.28 & -0.94 & 0.38 \\
\hline & Clarkfork 3 - Wasatch 0 & 1.12 & 1.39 & 0.71 & 2.07 \\
\hline & Wasatch 0 - Wasatch $1 / 2$ & -0.63 & -1.02 & -1.78 & -0.26 \\
\hline \multirow[t]{5}{*}{ NTI } & Tiffanian 6 - Clarkfork 1 & -0.95 & -0.50 & -4.87 & 3.87 \\
\hline & Clarkfork 1 - Clarkfork 2 & -0.09 & -0.09 & -1.68 & 1.50 \\
\hline & Clarkfork 2 - Clarkfork 3 & -0.21 & -0.23 & -0.89 & 0.43 \\
\hline & Clarkfork 3 - Wasatch 0 & 0.84 & 0.96 & 0.32 & 1.61 \\
\hline & Wasatch 0 - Wasatch $1 / 2$ & -0.37 & -0.39 & -1.11 & 0.34 \\
\hline \multirow[t]{2}{*}{$\mathrm{BM}_{\text {dist }}$} & Tiffanian 6 - Clarkfork 1 & -0.31 & -2.68 & -8.61 & 3.25 \\
\hline & Clarkfork 1 - Clarkfork 2 & 0.63 & 1.03 & -0.60 & 2.66 \\
\hline
\end{tabular}




\begin{tabular}{|c|c|c|c|c|c|}
\hline & Clarkfork 2 - Clarkfork 3 & -0.19 & -0.40 & -1.07 & 0.27 \\
\hline & Clarkfork 3 - Wasatch 0 & -0.32 & -0.65 & -1.27 & -0.02 \\
\hline & Wasatch 0 - Wasatch $1 / 2$ & 0.12 & 0.22 & -0.50 & 0.94 \\
\hline \multirow[t]{5}{*}{$\beta$ diversity } & Tiffanian 6 - Clarkfork 1 & -0.08 & -0.68 & -2.02 & 0.65 \\
\hline & Clarkfork 1 - Clarkfork 2 & 0.05 & 0.47 & -0.14 & 1.08 \\
\hline & Clarkfork 2 - Clarkfork 3 & -0.01 & -0.12 & -0.55 & 0.31 \\
\hline & Clarkfork 3 - Wasatch 0 & 0.08 & 0.84 & 0.42 & 1.26 \\
\hline & Wasatch 0 - Wasatch $1 / 2$ & 0.01 & 0.18 & -0.36 & 0.72 \\
\hline
\end{tabular}

(A) With (B) without taxa that first occur during the PETM (Wasatch 0). Gray cells represent comparisons before and during the PETM. 
Table 4. Standardized difference between the among-bin null and observed values for all community assembly metrics calculated using Cohen's D. Among-bin null models were generated by shuffling sites equiprobably among time bins. (A) With (B) without taxa that first occur during the PETM (Wasatch 0). Gray cells represent the PETM.

\begin{tabular}{|c|c|c|c|c|}
\hline Metric & NALMA & Effect Size & Upper $95 \%$ CI & Lower $95 \% \mathrm{CI}$ \\
\hline \multirow[t]{6}{*}{ NRI } & Tiffanian 6 & -16.07 & -18.72 & -13.43 \\
\hline & Clarkfork 1 & -12.62 & -14.87 & -10.37 \\
\hline & Clarkfork 2 & -3.96 & -4.59 & -3.33 \\
\hline & Clarkfork 3 & -2.82 & -3.40 & -2.24 \\
\hline & Wasatch 0 & 5.71 & 4.84 & 6.58 \\
\hline & Wasatch $1 / 2$ & 3.31 & 2.58 & 4.04 \\
\hline \multirow[t]{6}{*}{ NTI } & Tiffanian 6 & -6.03 & -7.67 & -4.38 \\
\hline & Clarkfork 1 & -10.43 & -12.45 & -8.40 \\
\hline & Clarkfork 2 & -5.43 & -6.32 & -4.55 \\
\hline & Clarkfork 3 & -3.31 & -3.93 & -2.69 \\
\hline & Wasatch 0 & 2.42 & 1.85 & 2.99 \\
\hline & Wasatch $1 / 2$ & 1.94 & 1.30 & 2.58 \\
\hline \multirow[t]{6}{*}{$\mathrm{BM}_{\mathrm{dist}}$} & Tiffanian 6 & 0.00 & -1.39 & 1.39 \\
\hline & Clarkfork 1 & 0.00 & -1.39 & 1.39 \\
\hline & Clarkfork 2 & 0.00 & -0.49 & 0.49 \\
\hline & Clarkfork 3 & 0.00 & -0.41 & 0.41 \\
\hline & Wasatch 0 & -0.02 & -0.45 & 0.40 \\
\hline & Wasatch $1 / 2$ & 0.10 & -0.45 & 0.64 \\
\hline \multirow[t]{6}{*}{$\beta$ diversity } & Tiffanian 6 & 0.41 & -0.72 & 1.54 \\
\hline & Clarkfork 1 & -1.25 & -1.73 & -0.78 \\
\hline & Clarkfork 2 & -0.90 & -1.25 & -0.56 \\
\hline & Clarkfork 3 & -1.09 & -1.34 & -0.84 \\
\hline & Wasatch 0 & -0.24 & -0.55 & 0.06 \\
\hline & Wasatch $1 / 2$ & -0.35 & -0.76 & 0.05 \\
\hline \multirow[t]{6}{*}{ NRI } & Tiffanian 6 & -16.55 & -19.24 & -13.85 \\
\hline & Clarkfork 1 & -9.67 & -11.63 & -7.72 \\
\hline & Clarkfork 2 & -4.66 & -5.47 & -3.85 \\
\hline & Clarkfork 3 & -1.99 & -2.51 & -1.47 \\
\hline & Wasatch 0 & 5.79 & 4.91 & 6.66 \\
\hline & Wasatch $1 / 2$ & 2.06 & 1.42 & 2.70 \\
\hline \multirow[t]{2}{*}{ NTI } & Tiffanian 6 & -6.03 & -7.67 & -4.38 \\
\hline & Clarkfork 1 & -10.43 & -12.45 & -8.40 \\
\hline
\end{tabular}




\begin{tabular}{lllll} 
& Clarkfork 2 & $\mathbf{- 5 . 4 3}$ & -6.32 & -4.55 \\
Clarkfork 3 & $\mathbf{- 3 . 3 1}$ & -3.93 & -2.69 \\
Wasatch 0 & $\mathbf{2 . 7 0}$ & 2.12 & 3.29 \\
Wasatch 1/2 & $\mathbf{1 . 4 5}$ & 0.83 & 2.06 \\
BM $_{\text {dist }}$ & & & 1.39 \\
Tiffanian 6 & 0.00 & -1.39 & 1.39 \\
Clarkfork 1 & 0.00 & -1.39 & 0.49 \\
Clarkfork 2 & 0.00 & -0.49 & 0.41 \\
Clarkfork 3 & 0.00 & -0.41 & 0.19 \\
Wasatch 0 & -0.23 & -0.66 & 0.56 \\
Wasatch 1/2 & 0.02 & -0.52 & 1.55 \\
Tiversity & & -0.72 & -0.70 \\
& Clarkfork 1 & 0.41 & -1.66 & -0.52 \\
Clarkfork 2 & $\mathbf{- 1 . 1 8}$ & -1.22 & -0.79 \\
Clarkfork 3 & -0.87 & -1.29 & 0.09 \\
Wasatch 0 & $\mathbf{- 1 . 0 4}$ & -0.52 & 0.45 \\
Wasatch 1/2 & -0.22 & -0.41 & \\
\hline
\end{tabular}




\section{Figure Legends}

FIGURE 1. (A) Pairwise taxonomic similarity (Jaccard similarity) among temporally adjacent North American Land Mammal Ages. (B) Mean pairwise phylogenetic distances among species in the regional pool for each North American Land Mammal Age. Estimates of first and last appearance rates of Paleocene-Eocene mammals in the Bighorn Basin of Wyoming using Pradel Seniority capture-recapture models (CMR) including gamma diversity (black dotted line) (C) and alpha diversity +/- the standard deviation (D). The best fit CMR model was one holding extinction constant with time variable rates of first appearance and sampling or preservation. The Paleocene-Eocene Thermal Maximum is highlighted in dark gray. Tiff $6=$ Tiffanian 6 , CF1 $=$ Clarkfork 1, CF2 = Clarkfork 2, CF3 = Clarkfork 3, Was0 = Wasatch 0, Was1-2 = Wasatch 1-2.

FIGURE 2. Body mass frequency distributions of Paleocene-Eocene mammals of North America. Kolmogorov-Smirnov two-sample tests indicate no significant change in the shape of the body mass distributions before and after the PETM (i.e., Clarkfork 3 vs. Wasatch 0 (PETM), $\mathrm{D}=0.127, \mathrm{p}=0.84$; see Table 2 for all pairwise comparisons among NALMAs).

FIGURE 3. Change in phylogenetic diversity measured using the Net Relatedness Index (NRI; A) and Nearest Taxon Index (NTI; B), functional diversity measured using body mass dispersion (C), and mean taxonomic dissimilarity (D) of North American mammals across the Paleocene-Eocene Thermal Maximum (PETM; delineated by gray shading) in Wyoming. The tree used to calculate the NRI and NTI was dated using the cal3 method. NRI and NTI were calculated as the mean pairwise distance and nearest taxon distance, respectively, for all localities across the 1000 trees in the posterior distribution standardized to 1000 iterations of taxa shuffled equiprobably among sites within each time bin. Box plots therefore represent the distribution of 1000 values of NRI and NTI per site. Black horizontal lines indicate the expected 
mean of zero for the randomizations within each time bin. Taxonomic similarity was calculated as the mean distance from the PCoA centroid using the Jaccard Index. For body mass dispersion and taxonomic similarity, the box plots represent the distribution of values calculated for each locality. Gray circles with light gray bars show the mean of the null models where sites were shuffled among time bins $+/$ - their standard deviation. $d$ represents the value of Cohen's D for the main comparison, pre-PETM and PETM NALMAs. Other values for $d$ for comparisons between NALMAs can be found in Table 3. Tiff $6=$ Tiffanian $6, \mathrm{CF} 1=$ Clarkfork $1, \mathrm{CF} 2=$ Clarkfork 2, CF3 = Clarkfork 3, Was0 = Wasatch 0, Was1-2 = Wasatch 1-2.

Appendix I. 1000 time-scaled phylogenetic trees constructed using the cal3 method in the paleotree R package (Bapst, 2012). 

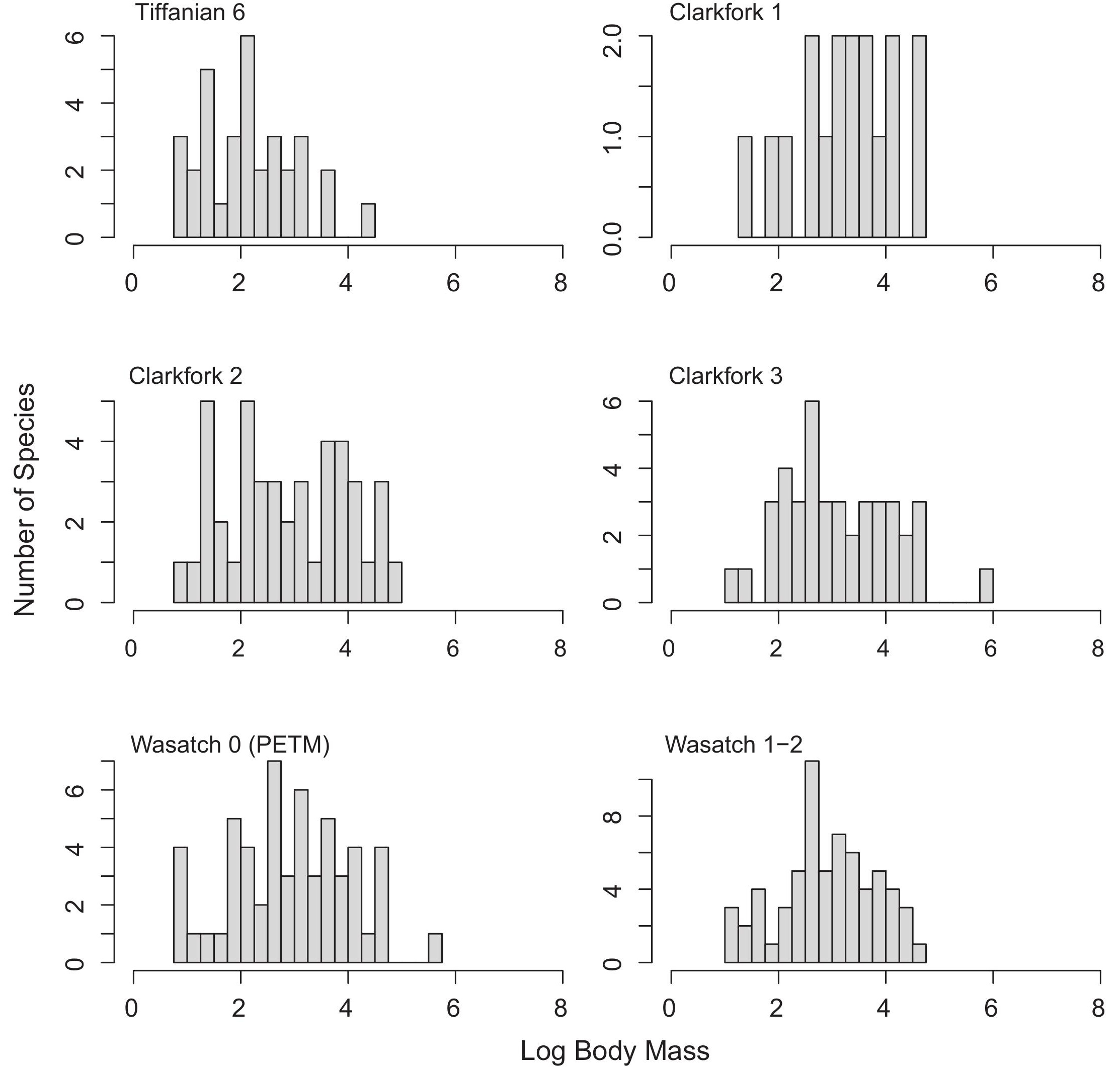


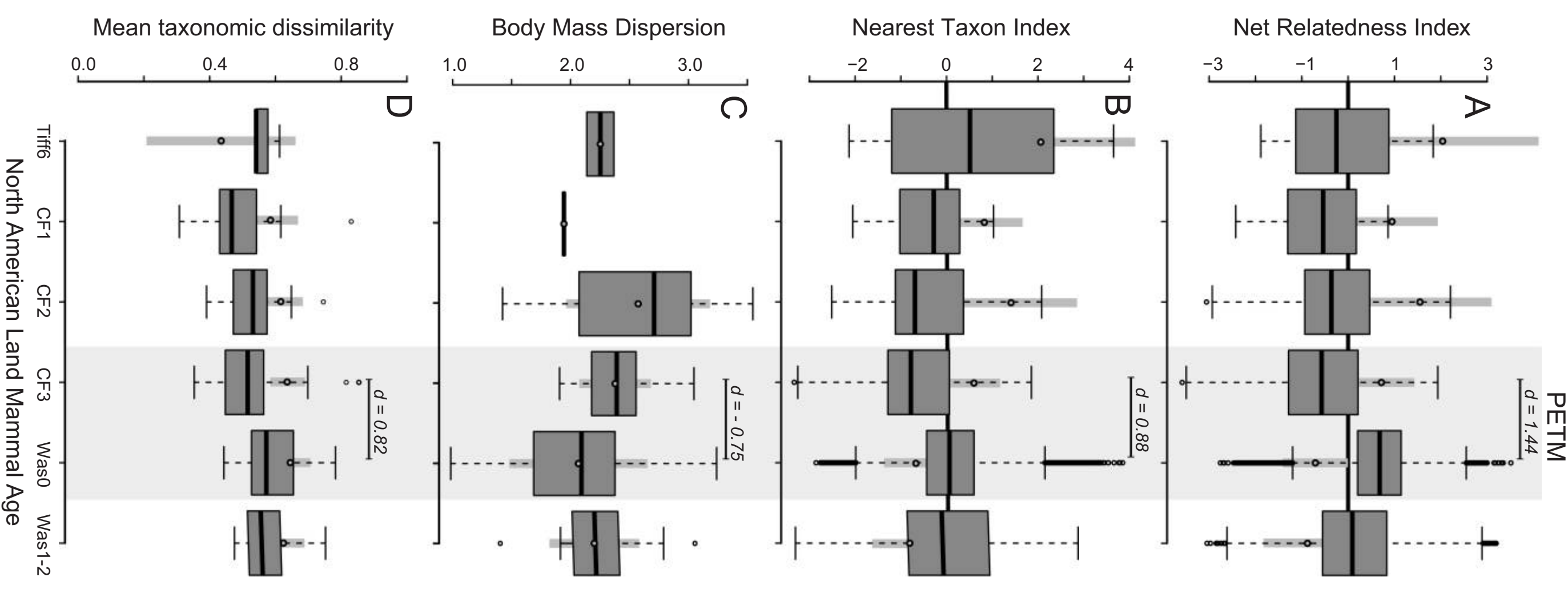


PETM Mammal Community Structure

\section{The American Naturalist}

\section{Mammal community structure through the Paleocene-Eocene Thermal Maximum}

Keywords: invasion, mammals, phylogenetic community structure, body size, beta diversity

Danielle Fraser ${ }^{1,2,3, *}$ and S. Kathleen Lyons ${ }^{4}$

Affiliations: ${ }^{1}$ Palaeobiology, Canadian Museum of Nature, PO Box 3443 Stn “D”, Ottawa ON K1P 6P4

${ }^{2}$ Biology \& Earth Sciences, Carleton University, 1125 Colonel By Drive, Ottawa, Ontario, Canada K1S 5B6

${ }^{3}$ Department of Paleobiology, Smithsonian Institution, National Museum of Natural History, $10^{\text {th }}$ and Constitution NW, Washington, DC 20560-0121

${ }^{4}$ School of Biological Sciences, University of Nebraska Lincoln, Lincoln, NE, 68502 USA

*Dfraser@nature.ca 
PETM Mammal Community Structure

\section{SUPPLEMENTAL TABLES}

Table S1. Species with first occurrences during Wasatch 0 (PETM).

\begin{tabular}{|c|c|}
\hline Species & Clade \\
\hline Chriacus gallinae & Arctocyonidae \\
\hline Bunophorus robustus & Artiodactyla \\
\hline Diacodexis metsiacus & Artiodactyla \\
\hline Simpsonodus chacensis & Artiodactyla \\
\hline Miacis exiguus & Carnivora \\
\hline Barylambda faberi & Cimolesta \\
\hline Esthonyx bisulcatus & Esthonychidae \\
\hline Prototomus martis & Hyaenodontidae \\
\hline Prototomus secundarius & Hyaenodontidae \\
\hline Hyopsodus loomisi & Hyopsodontidae \\
\hline Hyopsodus lysitensis & Hyopsodontidae \\
\hline Hyopsodus powellianus & Hyopsodontidae \\
\hline Hyopsodus simplex & Hyopsodontidae \\
\hline Palaeictops bicuspis & Leptictidae \\
\hline Parectypodus lunatus & Multituberculata \\
\hline Palaeosinopa incerta & Pantolestidae \\
\hline Peradectes elegans & Paradectidae \\
\hline Simpsonlemur jepseni & Paraomomyidae \\
\hline Cardiolophus radinskyi & Perissodactyla \\
\hline Sifrhippus grangeri & Perissodactyla \\
\hline Xenicohippus grangeri & Perissodactyla \\
\hline Copecion brachypternus & Phenacodontidae \\
\hline Cantius abditus & Primates \\
\hline Cantius frugivorus & Primates \\
\hline Microsyops latidens & Primates \\
\hline Tetonius matthewi & Primates \\
\hline Lophiparamys debequensis & Rodentia \\
\hline Paramys copei & Rodentia \\
\hline Paramys taurus & Rodentia \\
\hline Thisbemys perditus & Rodentia \\
\hline Talpavoides dartoni & Tribosphenida \\
\hline Viverravus lutosus & Viverravidae \\
\hline
\end{tabular}


PETM Mammal Community Structure

Table S2. Occurrence summary for each NALMA and species.

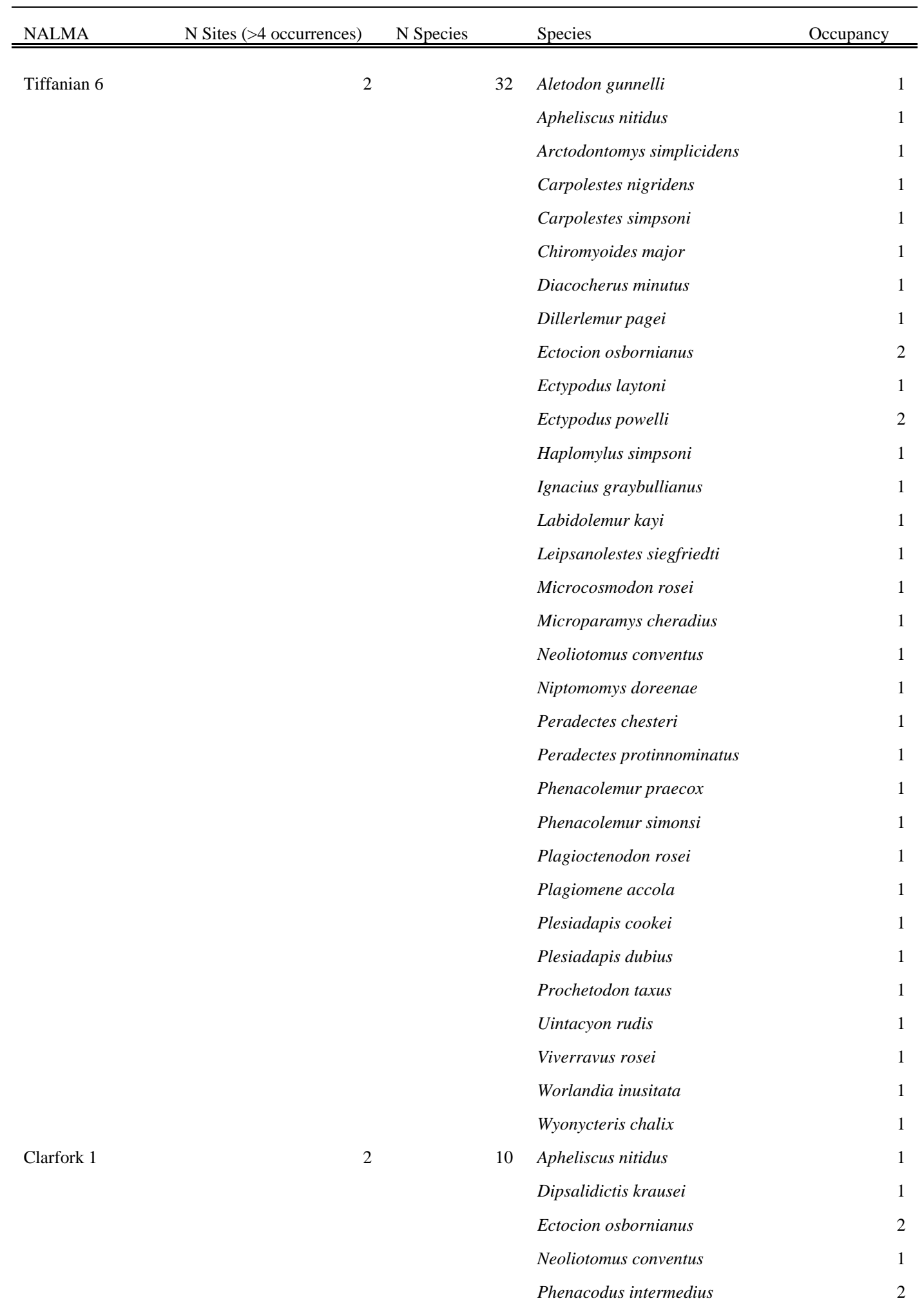




\section{PETM Mammal Community Structure}

Clarkfork 2

16

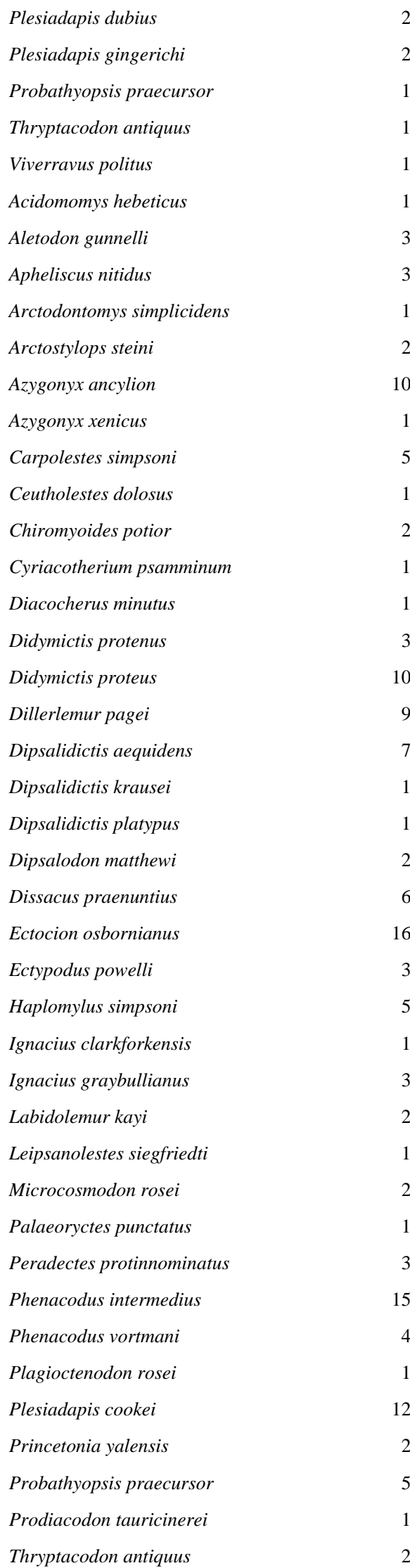

1

1

3

3

1

2

0

1

5

1

2

1

1

3

10

9

7

1

1

2

6

16

3

5

1

3

2

1

2

1

3

15

4

1

12

2

5

1

2 


\section{PETM Mammal Community Structure}

Clarkfork 3

2

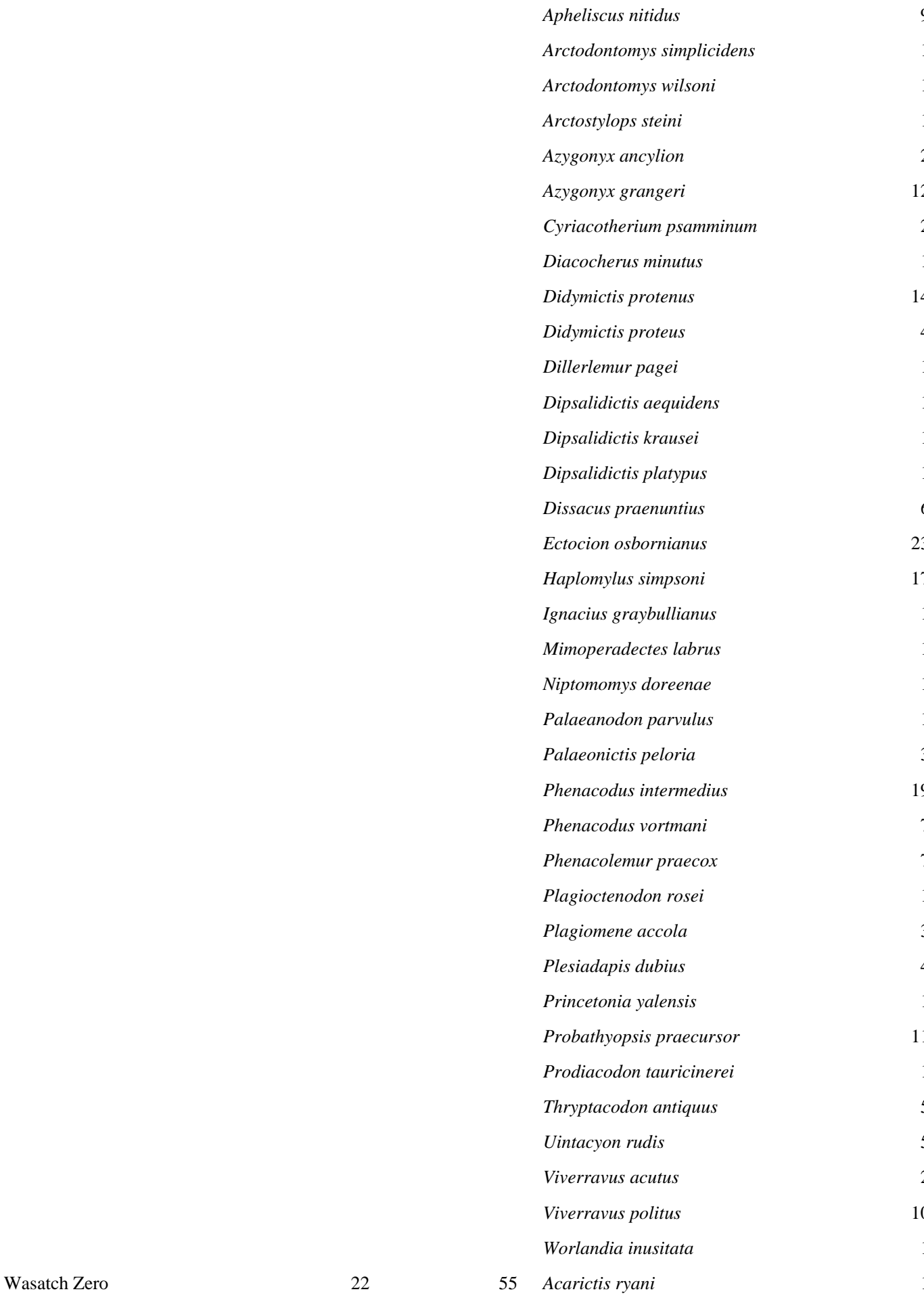


PETM Mammal Community Structure

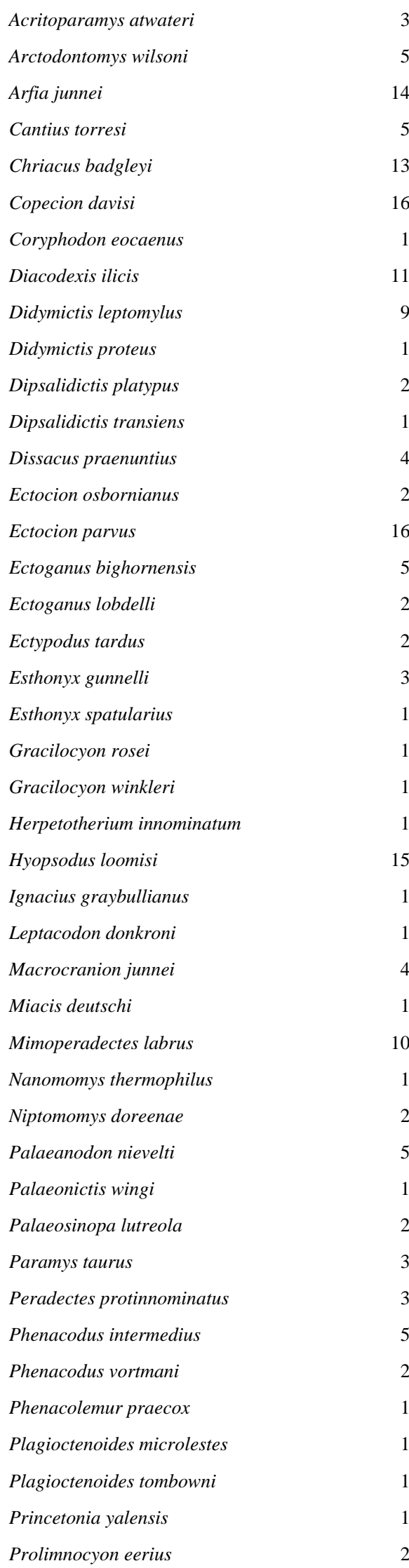

14

5

3

16

1

11

9

1

2

1

4

2

6

5

2

2

3

1

1

1

1

15

1

1

4

1

10

1

2

5

1

2

3

3

5

2

1

1

1

1

2 


\section{PETM Mammal Community Structure}

Wasatch one-two

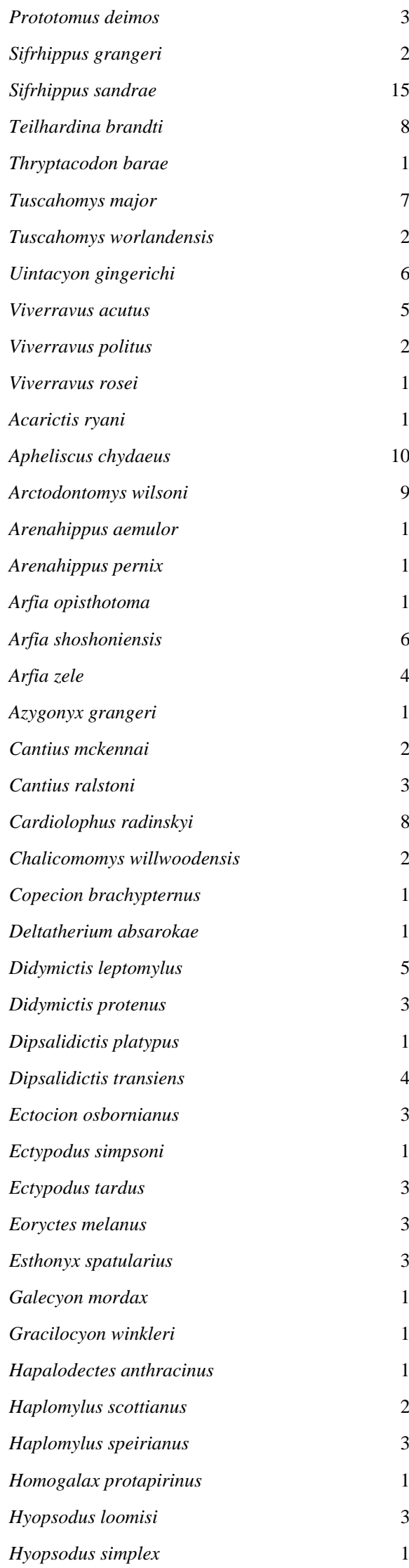

5

8

2

6

5

2

1

10

9

1

1

6

4

1

2

3

8

2

1

1

3

1

4

3

1

3

3

3

1

1

1

2

3 
PETM Mammal Community Structure

\begin{tabular}{|c|c|}
\hline Ignacius graybullianus & 3 \\
\hline Miacis deutschi & 1 \\
\hline Miacis exiguus & 1 \\
\hline Micromomys antelucanus & 2 \\
\hline Microparamys hunterae & 1 \\
\hline Microsyops angustidens & 1 \\
\hline Neoliotomus ultimus & 7 \\
\hline Oxyaena gulo & 2 \\
\hline Palaeanodon nievelti & 7 \\
\hline Palaeonictis occidentalis & 1 \\
\hline Parapternodus antiquus & 1 \\
\hline Parectypodus lunatus & 1 \\
\hline Phenacodus vortmani & 1 \\
\hline Plagiomene accola & 1 \\
\hline Plagiomene multicuspis & 1 \\
\hline Prolimnocyon atavus & 1 \\
\hline Prolimnocyon haematus & 5 \\
\hline Prototomus deimos & 1 \\
\hline Prototomus martis & 6 \\
\hline Prototomus phobos & 5 \\
\hline Pseudotetonius ambiguus & 1 \\
\hline Sifrhippus grangeri & 11 \\
\hline Teilhardina americana & 2 \\
\hline Tetonius matthewi & 1 \\
\hline Thryptacodon antiquus & 3 \\
\hline Tinimomys graybulliensis & 1 \\
\hline Uintacyon massetericus & 2 \\
\hline Viverravus acutus & 9 \\
\hline Viverravus politus & 5 \\
\hline Viverravus rosei & 3 \\
\hline Wyolestes apheles & 1 \\
\hline
\end{tabular}




\section{SUPPLEMENTAL FIGURES}
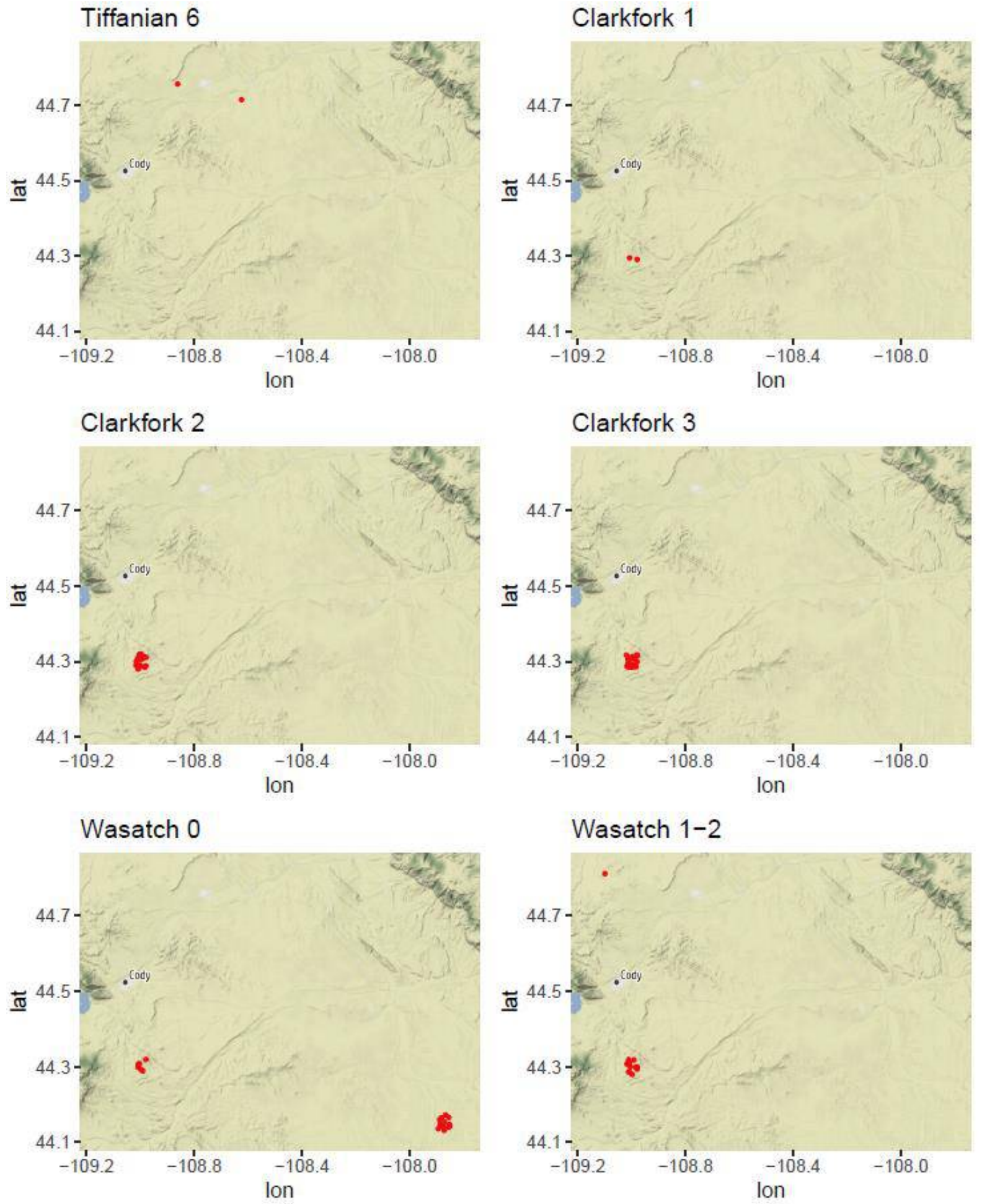

Figure S1. Geographic locations for all sites in the present study. 

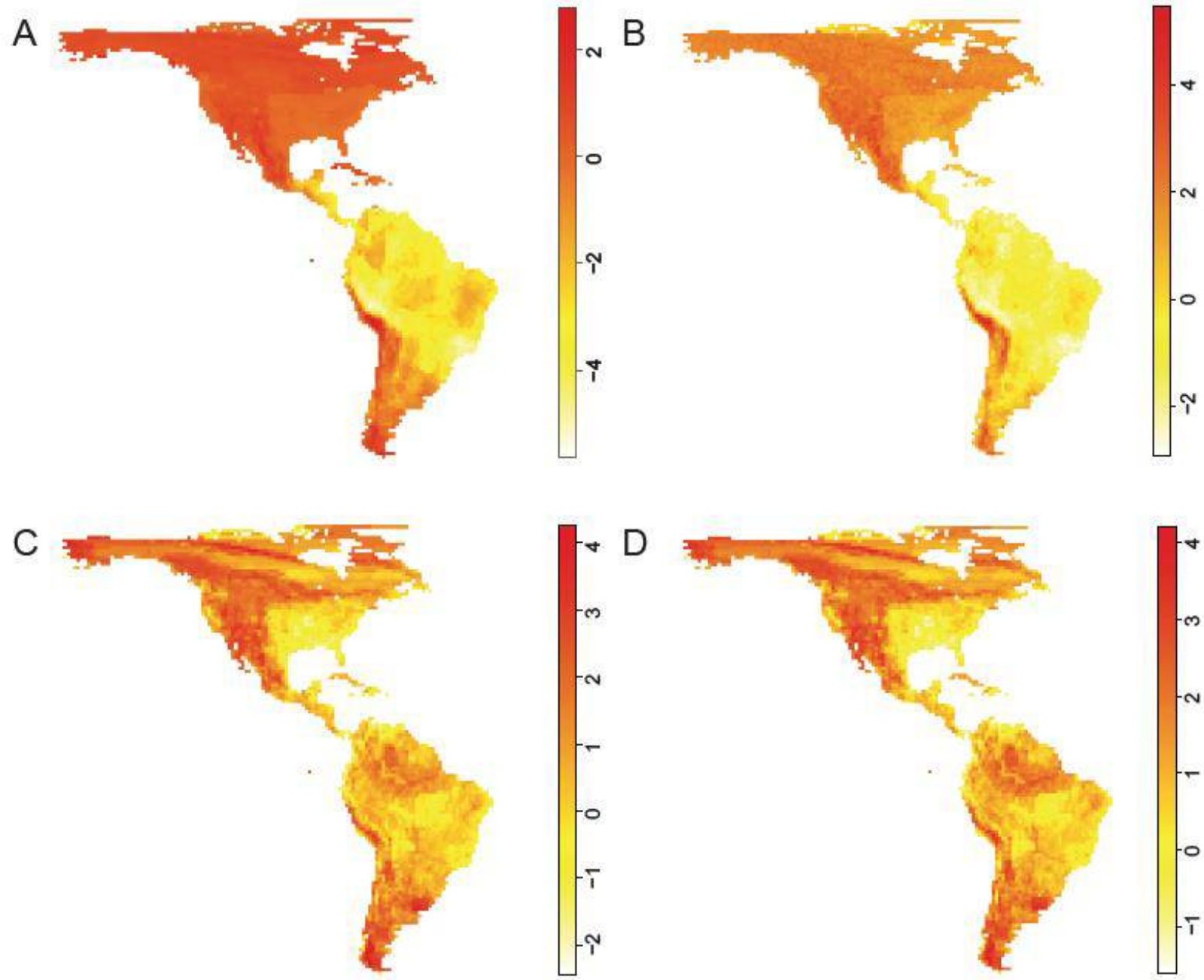

FIGURE S2. Latitudinal patterns of phylogenetic diversity for modern Western Hemisphere non-volant mammals. (A) Net Relatedness Index (NRI) using a simple taxon shuffling algorithm to generate null species assemblages, (B) NRI using the independent swap algorithm, (C) Nearest Taxon Index (NTI) using a simple taxon shuffling algorithm, and (D) NTI using the independent swap algorithm. 


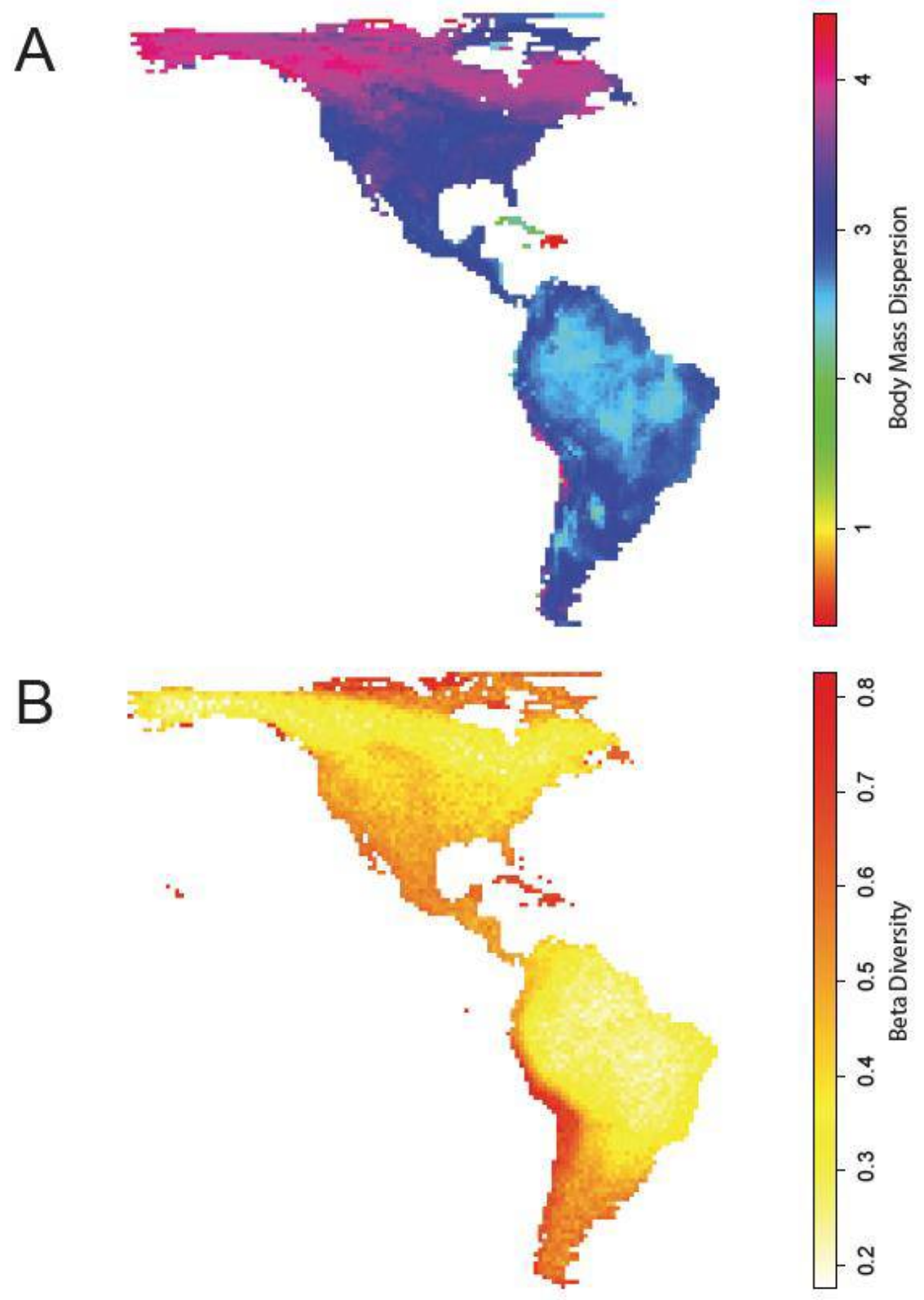

FIGURE S3. Latitudinal patterns of body mass dispersion (A), and $\beta$ diversity (B) for modern Western Hemisphere non-volant mammals. $\beta$ diversity was calculated using the Jaccard Index. 


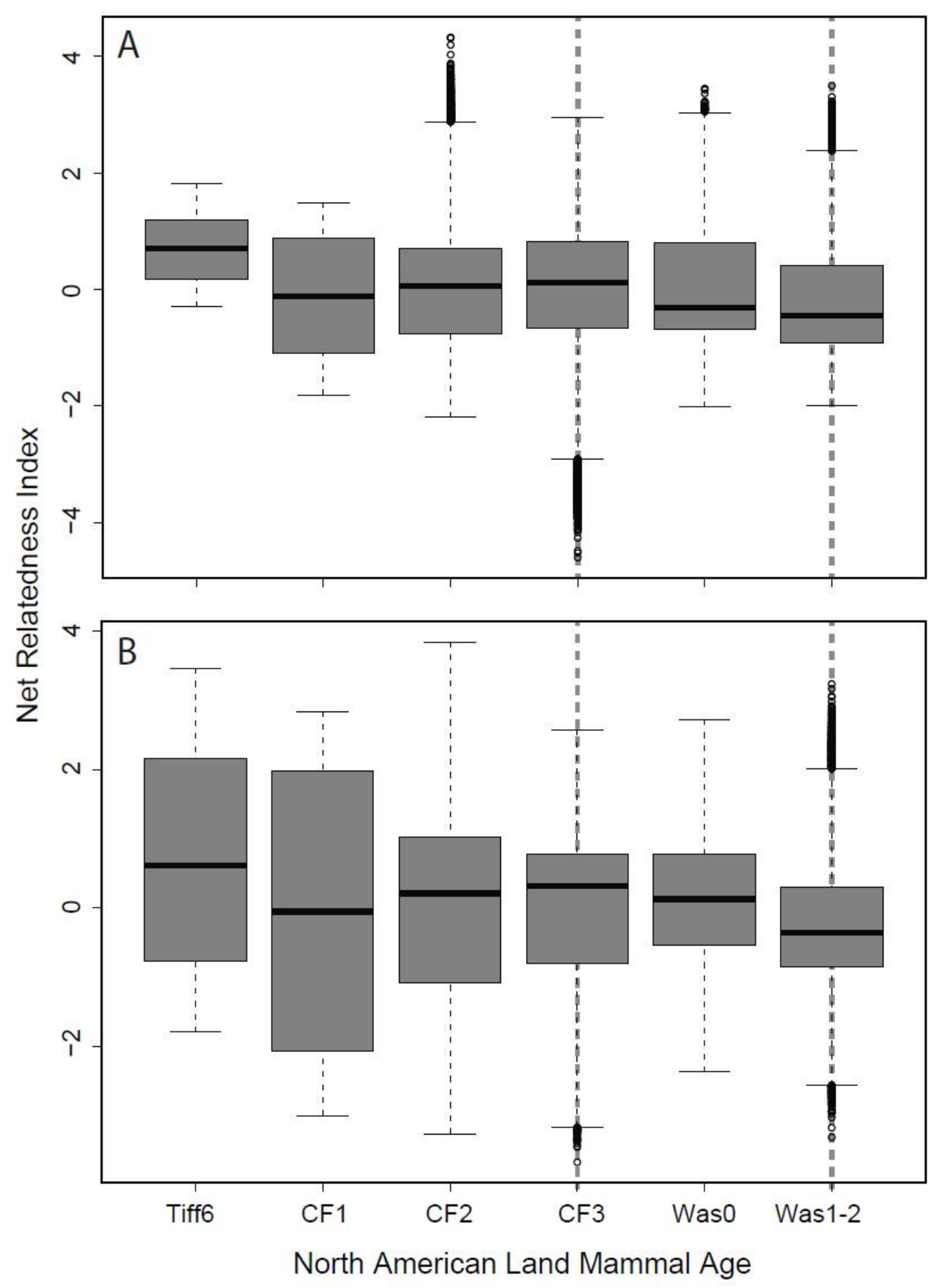

FIGURE S4. Change in mammal phylogenetic diversity (Net Relatedness Index) the late Paleocene to early Eocene in Wyoming (PETM is delineated by dotted lines) as calculated using the minimum branch length dated phylogenies (A) and all branches additive dated phylogenies (B). NRI and NTI were calculated as the mean pairwise distance and nearest taxon distance, 
PETM Mammal Community Structure

respectively, for all localities across the 1000 trees in the posterior distribution standardized to 1000 iterations of taxa shuffled equiprobably among sites within each time bin. Box plots therefore represent the distribution of 1000 values of NRI and NTI per site. 


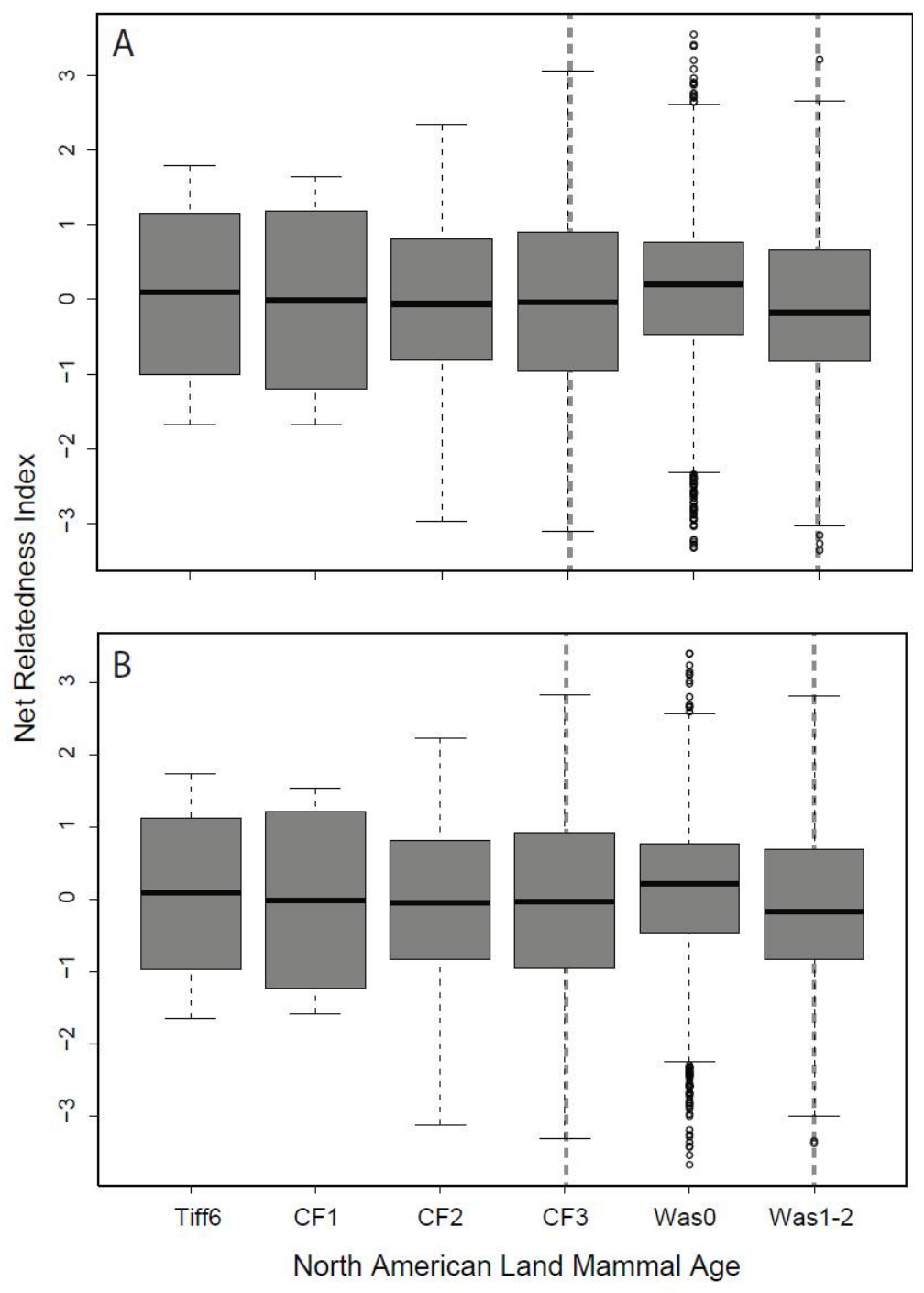

FIGURE S5. Change in mammal phylogenetic diversity (Net Relatedness Index) from the late Paleocene to early Eocene in Wyoming (PETM is delineated by dotted lines) as calculated after degrading one of the cal3 dated phylogenies by $25 \%$ (A) and 50\% (B). NRI and NTI were calculated as the mean pairwise distance and nearest taxon distance, respectively, for all localities across the 1000 trees in the posterior distribution standardized to 1000 iterations of taxa shuffled equiprobably among sites within each time bin. Box plots therefore represent the distribution of 1000 values of NRI and NTI per site. 


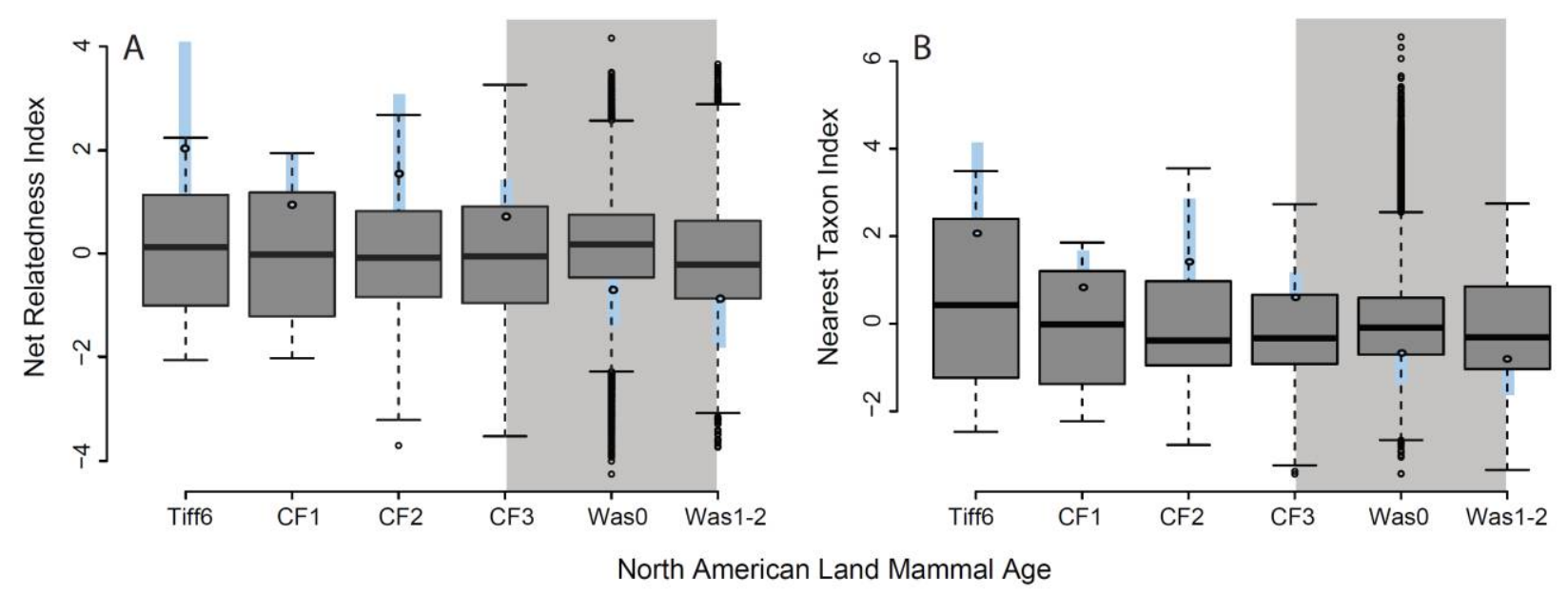

FIGURE S6. Change in phylogenetic diversity measured using the Net Relatedness Index (NRI;

A) and Nearest Taxon Index (NTI; B) of North American mammals across the Paleocene-Eocene Thermal Maximum (PETM; delineated by gray shading) in Wyoming. NRI and NTI were calculated as the mean pairwise distance and nearest taxon distance, respectively, for all localities across the 1000 trees in the posterior distribution standardized to 1000 iterations of the independent swap algorithm within each time bin. Box plots therefore represent the distribution of 1000 values of NRI and NTI per site. Gray circles with blue bars show the mean of the null models where sites were shuffled among time bins $+/$ - their standard deviation. The tree used to calculate the NRI and NTI was dated using the cal3 method. Tiff $6=$ Tiffanian 6, CF1 $=$ Clarkfork $1, \mathrm{CF} 2=$ Clarkfork $2, \mathrm{CF} 3=$ Clarkfork 3 , Was0 $=$ Wasatch 0, Was1-2 $=$ Wasatch 1-2 

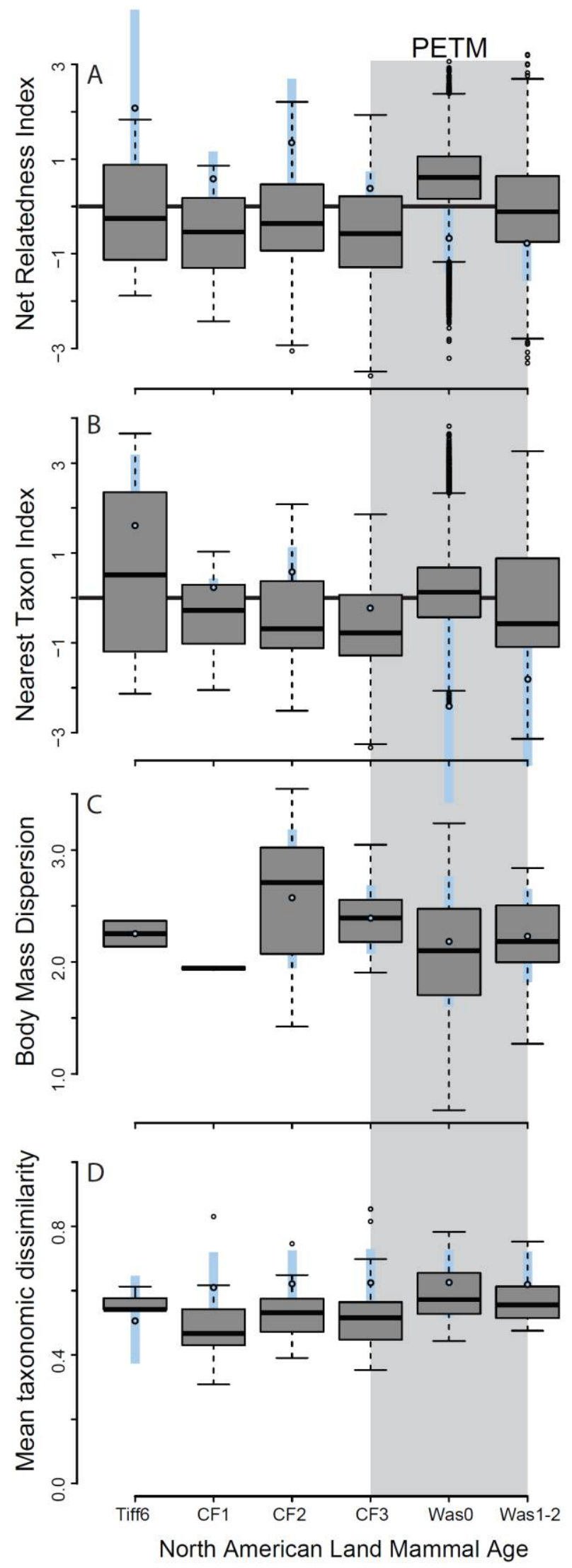
Figure S7. Change in phylogenetic diversity measured using the Net Relatedness Index (NRI; A) and Nearest Taxon Index (NTI; B), functional diversity measured using body mass dispersion (C), and mean taxonomic dissimilarity (D) of North American non-immigrant mammals across the Paleocene-Eocene Thermal Maximum (PETM; delineated by gray shading) in Wyoming. The tree used to calculate the NRI and NTI was dated using the cal3 method. NRI and NTI were calculated as the mean pairwise distance and nearest taxon distance, respectively, for all localities across the 1000 trees in the posterior distribution standardized to 1000 iterations of taxa shuffled equiprobably among sites within each time bin. Box plots therefore represent the distribution of 1000 values of NRI and NTI per site. Taxonomic similarity was calculated as the mean distance from the PCoA centroid using the Jaccard Index. Black horizontal lines indicate the value at which NRI and NTI are indistinguishable from within-bin null expectations. For body mass dispersion and taxonomic similarity, the box plots represent the distribution of values calculated for each locality. Gray circles with blue bars show the mean of the null models where sites were shuffled among time bins + /- their standard deviation.. Tiff $6=$ Tiffanian $6, \mathrm{CF} 1=$ Clarkfork 1, CF2 = Clarkfork 2, CF3 = Clarkfork 3, Was0 = Wasatch 0, Was1-2 = Wasatch 1-2. 